\title{
La participación del bajo clero en el excedente agrario vasco y riojano (1545-1775)
}

\section{The involvement of lower clergy in the agricultural surplus of Basque country and Rioja (1545-1775)}

\author{
ELENA CATALÁN MARTÍNEZ \\ Universidad del País Vasco
}

\begin{abstract}
RESUMEN
En este trabajo se analiza la evolución del producto agrario que percibe el clero parroquial entre 1545 y 1775. Para establecer el producto agrario de un servidor medio se ha de tener en cuenta tanto la cantidad y especies que percibe en concepto de diezmo, una vez deducidas las cargas que pesan sobre ellas, como el tipo de plaza que ocupa en la parroquia (beneficiado de entera, media o cuarta ración). Se ha comparado la cantidad anual percibida en especie con la que recibiría un vecino de su mismo pueblo y qué carga representa para la comunidad el mantenimiento de la clerecía local.

PALABRAS CLAVE: Diezmo, Renta Agraria, Bajo clero, Edad Moderna

Códigos JEL: N33, N53, N93, Z12

\section{ABSTRACT}

This piece of work analyzes the evolution of the agricultural product received by the lower clergy between 1545 and 1775 . To establish the annual income received by the parish priest, one must take into account both the quantity and the quantity in kind received as tithe, once all charges and the part set aside for the cathedral had been deducted. In the same way it is necessary to identify the place these priests occupied in the ecclesiastic hierarchy, since their incomes were closely related to this position. In this paper we compare the annual amount received in kind by an average priest and that received by a peasant in the same village. Eventually these figures give us the opportunity to determine how much the maintenance of the local clergy cost the community.

KEY WORDS: Tithe, Agrarian product, Low clergy, Modern Age

JEL Codes: N33, N53, N93, Z12
\end{abstract}




\section{Introducción ${ }^{1}$}

7 radicionalmente, la desigualdad en las sociedades preindustriales ha sido abordada desde una perspectiva estamental en la que la posibilidad de acceso al excedente agrario define en gran medida la pertenencia o no al grupo dirigente $^{2}$. La división social entre privilegiados y no privilegiados, aun respondiendo a una realidad aceptada, pierde riqueza interpretativa al minimizar la diversidad que se desarrolla en el interior de cada grupo. El clero constituye un magnífico observatorio desde el que profundizar en la desigualdad basada en los mecanismos que regulan la distribución de la renta dentro del colectivo, ya que se trata de un grupo muy heterogéneo, reglamentado y, sobre todo, excelentemente documentado.

El origen de este trabajo estuvo en la constatación, a través de las fuentes parroquiales del obispado de Calahorra y La Calzada, de que una parte importante de los clérigos de a pie no gozaban de los privilegios y el bienestar que en teoría les correspondía a los de su clase. La disparidad económica se producía tanto a nivel comarcal como parroquial, donde el reparto de todas las rentas eclesiásticas — beneficio- se hacía en función del tipo de plaza que ocupaba el clérigo. Por otra parte, existía una tendencia creciente a la acumulación de beneficios y al recurso de la financiación privada vía capellanías ${ }^{3}$, lo que sin duda contribuía a consolidar la imagen de un clero opulento, ocioso y casi siempre excesivo. La exigüidad de algunas rentas, el incremento de la presión fiscal sobre el colectivo, la dependencia del clero vasco de la nobleza local o el recurso continuado a la acumulación de prebendas, cuestionaban la pertenencia del bajo clero al grupo de los privilegiados ya que su situación económica no difería mucho de la de un campesino, tal y como atestiguaban numerosas fuentes ${ }^{4}$.

Para poder cuantificar la magnitud de este fenómeno, era necesario establecer la renta de un beneficiado tipo y determinar la distancia que le separaba tanto de sus feligreses como de un canónigo con residencia en la catedral. Dadas las características de las fuentes disponibles, el único punto de encuentro para todos ellos era el producto agrario que percibían o pagaban a través del diezmo, aunque sin entrar

[Fecha de recepción del original, 9 de marzo de 2009. Versión definitiva, 6 de octubre de 2009].

1 Este trabajo ha sido realizado con la ayuda del Plan Nacional I+D (2008-2011) del Ministerio de Ciencia e Innovación HAR2008-06048-C03-02. Quisiera agradecer a Igor Goñi, al comité editorial y a los evaluadores anónimos de Investigaciones de Historia Económica las sugerencias realizadas a este trabajo ya que han ayudado a mejorarlo sensiblemente.

2 En los últimos años se están haciendo esfuerzos importantes por definir una metodología que permita cuantificar la desigualdad en las sociedades preindustriales. Lindert, Milanovic y Williamson (2007).

3 Los capellanes eran clérigos financiados por un particular y no tenían derecho a participar en las rentas parroquiales aunque ejercieran sus funciones dentro de la misma.

4 Los testimonios de los obispos del norte peninsular sobre la situación de pobreza extrema y falta de formación de los clérigos son abundantísimos y han sido recogidos, entre otros, por Domínguez Ortiz (1979); Bilbao (1982); Fonseca (1992); Saavedra (1992) o Catalán (2000). 
en valoraciones monetarias puesto que no se conocen con exactitud los canales de comercialización y distribución que utilizaba cada uno, ni se podían aplicar las series de precios existentes en el conjunto del obispado ${ }^{5}$. La comparación de las principales especies que percibía un clérigo en su parroquia con las que le correspondían de promedio a una familia campesina, ha permitido situar el análisis en el primer estadio del proceso, aun cuando quedaban excluidas partidas importantes como las menucias (frutas, queso, huevos, animales de corral, etc.), los ingresos inherentes al ejercicio de las funciones pastorales o los procedentes de la pesca, la explotación del bosque o la actividad crediticia.

La cuantificación del producto agrario en especie ha posibilitado determinar, en primer lugar, la distancia que media entre las familias campesinas y los curas de su parroquia, así como las variaciones que haya podido sufrir en el largo plazo, sin la distorsión que produce la mayor capacidad de gestión del clero y, en segundo lugar, la carga que supuso para un pueblo el mantenimiento de su iglesia. Así mismo, se ha establecido una comparación en el nivel de vida de los clérigos de las diferentes circunscripciones gracias a la valoración monetaria que realizó el obispado de las rentas decimales.

\section{El marco geográfico y las fuentes}

El Obispado de Calahorra y La Calzada distó mucho de ser una entidad homogénea. Formaba parte del conjunto de iglesias insertas en economías de montaña, de agricultura mediocre y pervivencia de estructuras político-administrativas anteriores a la invasión musulmana, que se extendían desde Galicia hasta Cataluña a través de la vertiente norte de la cordillera Cantábrica y la sur de la pirenaica ${ }^{6}$.

A diferencia de otros obispados de este "arco cantábrico", el de Calahorra penetraba hacia el sur a través del valle del Ebro lo que le confirió una personalidad singular: doble sede episcopal; pervivencia del régimen patrimonial"7 Vizcaya y Guipúzcoa al margen de las directrices del obispo mientras que en Álava se reconocía mínimamente su autoridad; y La Rioja, con una agricultura más diversificada y productiva, que mantenía a la cúpula eclesiástica.

5 Las series existentes para otras zonas peninsulares — Reher y Ballesteros (1993); Martín Aceña (1992); Llopis, Jerez, Álvaro y Fernández (2000); Moreno Lázaro (2001) — no son utilizables para el obispado de Calahorra: en el País Vasco se debe tener en cuenta el hecho de que existe un sistema fiscal diferente así como aduanas que afectan al comercio con el interior; en La Rioja el tráfico de productos agrarios se realizaba en distintas monedas — real castellano, la libra navarra y la libra aragonesa-, diferentes sistemas metrólogicos y estaban afectados por peculiares sistemas impositivos derivados de los regímenes forales navarro, aragonés y vasco.

Fernández de Pinedo (2000), pp. 19-20.

Catalán (2000); Larrea Beobide (1995); Díaz de Durana (1998). 


\section{MAPA 1}

ORGANIZACIÓN ECLESIÁSTICA Y REGIONES NATURALES DEL OBISPADO DE CALAHORRA Y LA CALZADA

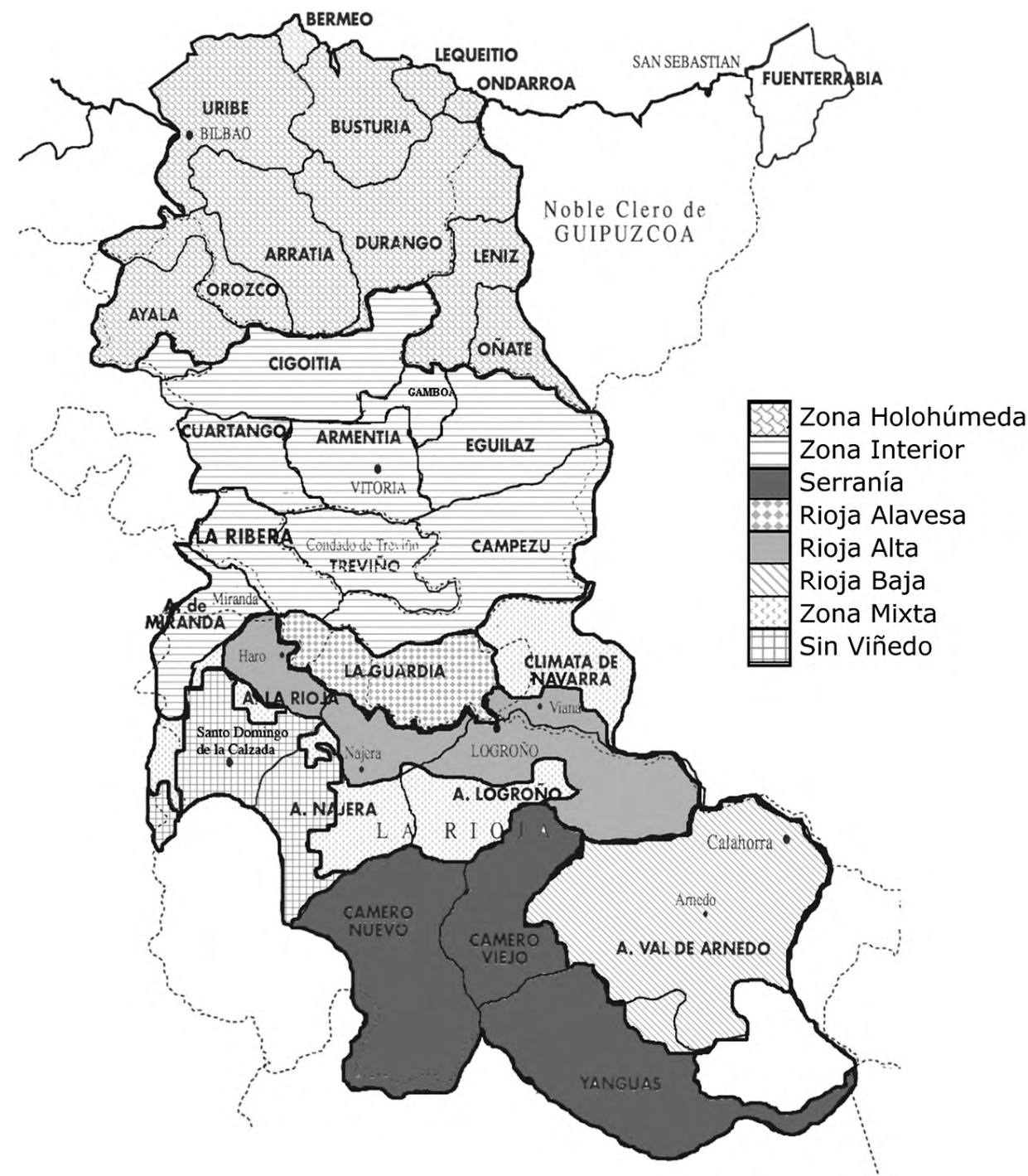

Fuente: Elaboración propia basada en la distribución geográfica de Bilbao y Fernández de Pinedo (1984) e lbáñez y Alonso (1996). En mayúsculas circunscripciones eclesiásticas.

Dada la complejidad del territorio era necesario delimitarlo en grandes áreas jurídico-geográficas que permitieran homogeneizar el análisis. De norte a sur se han establecido tres grandes zonas de similares características (Mapa 1): la marítima u 
holohúmeda, la interior cerealista y la riojana vinícola que comprende cuatro comarcas en función de la presencia de la vid: la comarca vitivinícola por excelencia - Rioja alavesa, Rioja alta y Rioja baja-, la mixta de cereal y vid; y la que carece de viñedo que engloba las sierras.

Así mismo, era preciso contar con fuentes que tuvieran en cuenta las peculiaridades del reparto decimal en cada una de las parroquias y que fueran homologables en todo el territorio ${ }^{8}$. Afortunadamente, el pago del subsidio y del excusado obligó a los obispados a elaborar una relación de bienes y rentas —averiguación de veros valores - de cada uno de los beneficiarios, incluidos los monasterios y patrones laicos. La primera averiguación, iniciada en 1542 y finalizada en 1545, recogía los datos de producción del quinquenio 1537-419. Tal y como señalaban Bilbao y Fernández de Pinedo, esta fuente presentaba numerosos problemas documentales, entre los que cabía destacar las abultadas partidas de menucias y dinero, si bien se la ha considerado válida para el cereal y para el vino ${ }^{10}$. Debemos añadir otra dificultad: la parte de los diezmos perteneciente a monasterios, dignidades y monarquía, se contabilizaba en un apartado específico agrupado por vicarías y arciprestazgos lo que representaba un problema para establecer el montante global del diezmo. A pesar de todas estas deficiencias, las averiguaciones de veros valores, nos han permitido determinar la composición de la renta agraria del bajo clero ya que detallan la cuantía y especies que percibían los beneficiados, curas, fábricas y patrones, así como su valoración monetaria a precios de tasa. Esta pesquisa se ha completado con la visita del Licenciado Gil efectuada en 1556 que, si bien proporciona una estimación general del valor del beneficio, ofrece datos muy valiosos sobre cada localidad como población, jurisdicción o reparto interno de rentas ${ }^{11}$.

En 1775, la renovación del sistema de concordias entre la Corona y la Iglesia hizo necesaria la averiguación de la base real imponible de las rentas que gravaban

8 Ni los libros de tazmías ni los de reparto de tercias — porción del diezmo percibida por la cúpula catedralicia-cumplían estos requisitos ya que no alcanzaban la suficiente cobertura geográfica ni desglosaban la porción que correspondía a cada partícipe de la masa decimal.

$9 \quad$ Archivo Catedralicio de Calahorra (ACC en adelante), Libro 271.

$10 \quad$ Bilbao y Fernández de Pinedo (1984), pp. 91-92.

11 Libro visita del Licenciado Gil, ACC, Libro 251. De ésta, hemos utilizado fundamentalmente los datos de vecindario y el número de raciones por cada parroquia. El número de beneficiados —clérigos con derecho a diezmo- parece bastante fiable, puesto que coincide con la información de los propios cabildos en esa época; sin embargo, la cuantificación del vecindario no tiene la misma calidad ya que los datos que ofrece, sobre todo en localidades importantes, están claramente redondeados. Aún así la proximidad cronológica con las averiguaciones de 1545, al inicio del crecimiento agrario, los hace más adecuados que los del censo de Millones de 1591, ya que este tampoco ofrece garantías plenas y no contempla al País Vasco. La visita del Licenciado Gil no incluye las vicarías vizcaínas (a excepción de Orduña y Orozco). Esta laguna se ha subsanado con datos procedentes de archivos parroquiales y recogidos en los apéndices de mi tesis doctoral — “Economía eclesiástica en Vizcaya durante el Antiguo Régimen”- y que no se publicaron en la versión de libro (Catalán, 2000) así como de otros recuentos de la época recogidos por Tomás González (1829). 
el subsidio y excusado. Los datos de esta pesquisa poseen una calidad excepcional y abarcan la totalidad del obispado. Para cada circunscripción se elaboraron dos libros: uno con las rentas gravadas por el subsidio y otro con las del excusado. En las del subsidio se consignaron, localidad a localidad, el nombre y cargo de cada miembro de la iglesia, reparto y datos monetarios de los diezmos, rentas de las fábricas, tierras beneficiales, anejos, rentas de aniversarios y memorias de misas, censos y juros, capellanías con expresión de su fundador, poseedor, bienes dotales, rentas y cargas. En los del excusado, se contabilizó la cuantía y especies de los diezmos que correspondían a cada partícipe, especificando cuáles procedían del acervo común, cuáles eran privativos de los cabildos, patrones o curas y las tierras que estaban exentas o que tributaban en menor proporción -normalmente por pertenecer a monasterios $^{12}$.

El hecho de que ambas averiguaciones tomaran como referencia la unidad básica de la organización eclesiástica - la parroquia—, ha facilitado su agrupación con criterios económicos en vez de eclesiásticos, y ha hecho posible el análisis de la estructura de la producción agraria en el largo plazo, cuantía del producto percibido por el clero parroquial y su equivalente familiar, así como la carga que supuso para un pueblo el mantenimiento de su iglesia. El resultado de este análisis debe considerarse con prudencia, al menos estimado en términos absolutos, ya que las averiguaciones no dejan de ser la base imponible de un tributo que, a su vez, refleja un ingreso de carácter fiscal como es el diezmo ${ }^{13}$.

Aunque el foco de atención de este trabajo se sitúa en el bajo clero, no se ha querido pasar por alto el esfuerzo que supuso para la clerecía llana el reconocimiento del señorío eclesiástico o la dependencia de un patrón laico. Para ello se han analizado los libros de administración de los cabildos catedrales que reflejan la gestión y comer-

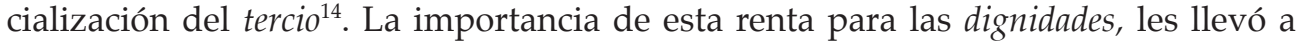

12 ACC, “Cuadernos del excusado 1771-1775”, legs. 3.864, 3.869, 3.891, 3.887, 2.838, 2.840, 2.842, 3.919, 3.893, $3.878,3.899,3.909,3.924,3.926,3.937,2.844,3.861,3.881$ / a, 3.897, 3.908/6, 3.932, 3.947, 3.962, 3.851, 3.953b, 3.883, 3.913 y 3.907 (en adelante se citan como Excusado 1771-75). Fuentes similares existen en todos los obispados castellanos y han sido utilizadas por la historiografía de forma dispar por su cercanía cronológica con el Catastro del Marqués de la Ensenada (que queda excluido por no incorporar a las provincias exentas). Entre los que las han usado destacan: Bilbao y Fernández de Pinedo (1984), Barreiro (2000), Barrio Gozalo (1982), Ibáñez (1999) o Catalán (2000).

13 La defraudación en el pago del diezmo existía desde la misma creación del impuesto. No obstante, hay indicios que permiten pensar que el fenómeno se intensificó desde los últimos decenios del siglo XVIII. LLopis y Sebastián (2007) y Rodríguez López-Brea (1995). El Obispado de Calahorra parece mantener una posición intermedia en el mantenimiento de los diezmos. Canales (1985) pp. 251-252. De hecho, las restituciones (las ocultaciones detectadas por la Iglesia y que debían ser pagadas en la cosecha siguiente) no aparecen en la documentación de tercias hasta mediada la década de 1780 y desde entonces se suceden en lento goteo, pero siempre en cantidades muy pequeñas. ACC, Libros 278 y 316.

14 ACC, Libros 327, 245, 318, 328, 338, 323, 256, 329, 243, 278 y 316. Archivo Catedralicio de Santo Domingo de la Calzada (ACSDC), cajas E9 a E 21, E47, E59. En adelante citados como Libros de Préstamos y Tercias. 
consignar de forma exhaustiva la gestión del ingreso, desde la recogida del fruto en las cillas hasta su comercialización y posterior reparto entre los perceptores. Este no se realizaba sobre el conjunto de lo percibido sino que cada localidad era tratada individualmente ya que cada una contribuía en una proporción según estuviese adscrita al acerbo personal del obispo, o al de los canónigos de una u otra catedral.

\section{El reparto del diezmo en el sistema beneficial}

Desde que los productos del diezmo se recogían en los campos hasta que llegaban a cada uno de los destinatarios pasaban por un complejo reparto jerárquico que, a pesar de las variaciones parroquiales, seguía un patrón bastante homogéneo ${ }^{15}$. En una distribución estándar, tras abonar las sacas, el tercio episcopal y la parte de la Corona, el clero parroquial percibiría en torno al 60\% de la masa decimal, una cantidad similar a la de las parroquias gallegas o cántabras ${ }^{16}$. De esta porción, y antes de proceder al prorrateo individual, los beneficiados debían hacer frente a una serie de gastos comunes derivados del ejercicio pastoral y de la gestión del diezmo.

No todos los miembros de una iglesia percibían el diezmo ni ingresaban la misma cantidad: únicamente los beneficios propios tenían pleno derecho a una porción de las rentas de la parroquia ${ }^{17}$. De estos solo uno, o dos si el número de feligreses era grande, tenía responsabilidades pastorales — cura animarum - por las que recibía un plus que era pagado por todos sus compañeros ${ }^{18}$. A partir del siglo $\mathrm{XV}$, el crecimiento de la población y la creencia en el poder absolutorio de la oración, originó un problema en la demanda de servicios religiosos: aunque la coyuntura favorable permitió la ampliación del número de los servidores en las parroquias, pronto resultaron insuficientes para satisfacer las necesidades de la feligresía. Además, no

15 El reparto decimal del Obispado de Calahorra y La Calzada ha sido estudiado con todo detalle por Ibáñez (1999), pp. 220-230.

16 En el caso Gallego lo percibido por el clero parroquial difiere enormemente de un obispado a otro oscilando entre el 77\% de Orense a menos del 40\% en la Coruña y Mondoñedo. Rey Castelao (1992) p. 149. En Cantabria la disparidad es enorme en función de la capacidad del obispo de Burgos de cobrar el tercio y la mayor o menor presencia de patrones laicos. Fonseca (1992) pp. 120-121. En Segovia, los beneficios curados percibían en torno al 26\% de la masa decimal (Barrio Gozalo (1982) p. 398), mientras que los de Córdoba solo alcanzan el 20\% (Muñoz Dueñas (1988) o el 17\% los de Cádiz (Morgado (1996). Nöel Salomon (1982), pp. 225-227, señala que en muchos pueblos de Castilla La Nueva no se mencionan a los párrocos entre los perceptores de diezmos.

17 Esta porción también se la denominaba ración y por asimilación, reciben este nombre los clérigos que tienen derecho a una parte de las rentas de la iglesia.

18 En La Rioja, la parte del curato solía ser una sexta parte de la ración entera mientras que en Álava consistía en una cantidad fija en trigo y/o cebada. ACC, Libro 271. Esta cantidad es inferior a la percibida por los párrocos segovianos — 50 a 67\% del diezmo en el siglo XVIII, según datos de Barrio Gozalo (1982) p. 414, o la de los gallegos que reciben por las mismas fechas el 59,7\%. Rey Castelao (1992) pp. 147-149. 
se podía aumentar su número indiscriminadamente, ya que esto hubiera supuesto una merma sustancial en la dotación de cada beneficio. Una de las soluciones que se adoptaron, para incrementar los efectivos de las parroquias sin alterar su nivel económico, fue la de crear o proveer las vacantes con dos o cuatro clérigos; es decir, la renta de un beneficio se dividía para dos individuos - medios beneficios - o para cuatro - cuartos. Las consecuencias de este sistema fueron evidentes ya que la distribución tanto de las cargas como de los estipendios se solía hacer de acuerdo con la ración entera ${ }^{19}$. Muchas de las obligaciones de los clérigos titulares, especialmente el servicio en las iglesias anejas, eran realizadas por los de menor rango y, más frecuentemente, por los expectantes o estudiantes que únicamente recibían un pequeño salario. Esta situación produjo un notable desequilibrio entre las rentas percibidas y el trabajo realizado.

Como se puede suponer, la renta de los beneficiados dependía mucho del número de raciones que estuvieran asignadas al dezmatorio; es decir, el número de clérigos que podía sustentar una población determinada. Aunque este guardaba una proporcionalidad directa con los habitantes y con el volumen diezmado, no siempre se respetaron los mínimos a cubrir y mucho menos en las iglesias de patronato o en las que predominaba la patrimonialidad. Como señala Ibáñez, al principio los cabildos tenían libertad para incorporar tantos miembros como considerasen oportuno, aun sin la renta adecuada ${ }^{20}$. El abuso llegó a tal punto que se llegaron a incorporar raciones que no alcanzaban la fanega de trigo, por lo que las autoridades eclesiásticas pusieron como límite mínimo de ampliación la cuarta parte de las rentas de la ración entera, corriendo los gastos jurídicos de la operación por cuenta del cabildo. En la década de 1530, se estableció que para realizar el cálculo de la ración entera se tuviera en cuenta, única y exclusivamente, los ingresos decimales dejando a un lado los devengados de las propiedades beneficiales, censos, aniversarios y derechos adventicios. A partir de Trento se restringió mucho más el acceso, al exigir a los candidatos un examen que les acreditase, además de contar con el refrendo del obispo. El hecho de que muchos de estos beneficios no contuviesen cláusula de exclusividad ni exigieran residencia, abría otra vía para completar las rentas anuales: la acumulación de varios cargos en manos de una misma persona que acababa teniendo unos ingresos considerables por esta vía. La crisis agraria del siglo XVII se encargó de ajustar las plantillas de los cabildos parroquiales y, por lo tanto, de mejorar las expectativas económicas de cada uno de ellos. Además, la iglesia de la contrarreforma alentó la financiación privada del clero: las capellanías colativas sirvieron de título

\footnotetext{
19 Para calcular las raciones que puede mantener una parroquia se debe contabilizar a dos beneficios medios por uno entero, dos cuartos por uno medio y así sucesivamente. La gradación existente en los cabildos y sus funciones en Catalán (2004), pp. 152-162.

20 Ibáñez (1999), pp. 283-284.
} 
de ordenación sacerdotal y por lo tanto constituyeron una magnífica vía de incremento de personal, aunque eso sí, sin derecho a la masa decimal.

\section{El producto agrario percibido por el clero parroquial y sus feligreses}

El contraste del producto agrario percibido por los eclesiásticos y su feligresía puede constituir un sólido punto de partida sobre el que construir un análisis comparado de los niveles de renta de ambos grupos sociales. La comparación se ha realizado a través de la cantidad de especies percibidas por unos y otros, y que se circunscriben, casi exclusivamente, a los cereales y al vino. De esta manera se obvian partidas importantes que tradicionalmente se percibían en dinero, así como otros ingresos procedentes del comercio, la industria o la actividad pastoral. Hay varias razones que explican este proceder: la primera es puramente metodológica, ya que la averiguación de veros valores de 1545 únicamente ofrece información detallada y fiable para cereales y vino; segunda, la valoración monetaria, ofrecida por la misma fuente, confirma que el diezmo de estas especies supone de media el $70 \%$ del total, aunque esta proporción varíe según la circunscripción que se analice; tercera, la propia Iglesia tomaba el diezmo como base para determinar los niveles de renta mínimos del clero parroquial, mientras que, en paralelo, la principal fuente de ingresos para los habitantes del mundo rural procedía de las cosechas ${ }^{21}$; cuarta, para poder otorgar un valor al producto agrario percibido por ambos colectivos se debería poder establecer las estrategias de comercialización de cada uno de ellos y los precios reales a los que consiguieron vender sus productos; quinta, en aquellas zonas con una fuerte presencia de actividades relacionadas con los sectores secundario y terciario, el clero participaba de las mismas a la vez que tenía una menor dependencia del diezmo por el dominio del patronato.

\subsection{La zona marítima}

Sin lugar a dudas, el producto agrario más modesto del obispado lo percibían los clérigos del área marítima. La exigüidad de este es consecuencia de la escasa dotación de factores agrícolas en el área y de la dedicación de una parte importante de

$21 \quad$ El importe de los derechos parroquiales incrementaron sustancialmente la renta de los eclesiásticos, siendo vital en aquellas zonas de agricultura pobre o dependencia de un patrón. Aún siendo relativamente sencillos de cuantificar, no se han introducido en los términos de comparación puesto que no se puede determinar de la misma manera los ingresos extras que los feligreses pudieran obtener por los más diversos medios. 
la población a actividades relacionadas con el comercio, el carboneo o la industria siderometalúrgica $^{22}$. A esto se debe añadir un dato organizativo que condicionará la evolución de las rentas del clero aunque no de la población: el predominio de las iglesias de patronato laical en las que el diezmo íntegro era percibido de forma exclusiva por sus propietarios, dejando para los servidores una pequeña porción de algunas especies que, en ocasiones, complementaban con una cantidad fija en dinero $^{23}$. Todo ello explica que, a mediados del siglo XVI, el producto agrario de los servidores de las parroquias del área fuese el más bajo de la diócesis, con un promedio anual de 12,47 hectolitros por ración; la mitad de lo obtenido por los curas alaveses y tres veces y media menos que los riojanos. Si consideramos la producción de grano, clérigos y vecinos estaban muy lejos de asegurar los mínimos de subsistencia que solo se alcanzaban con la incorporación de legumbres, manzanas y castañas. Esto condenaba a la región a una dependencia permanente de las importaciones de grano que, a su vez, permitieron el desarrollo de actividades relacionadas con el sector secundario y terciario ${ }^{24}$.

El crecimiento agrícola a lo largo del quinientos, que Bilbao y Fernández de Pinedo estiman entre el 30 y 40\%, debería haber supuesto una mejora sustancial de las cantidades que cada beneficiado percibía en concepto de diezmo ${ }^{25}$. En lugar de ello, el valor de cada ración mermó puesto que el número de clérigos no paró de crecer a lo largo del $\mathrm{XVI}^{26}$. La práctica totalidad del trigo y la cebada, así como la mitad de la borona — cereal similar al maíz-, estaban reservadas al patrón lo que explica que, para el conjunto de los cereales, una ración entera percibiera un $21 \%$ menos que una unidad de explotación.

La Iglesia intentó subsanar la carencia decimal a través de la explotación de otras actividades productivas en las que la autoridad del patrón no supusiese una injerencia interna. Así, las parroquias que estaban ubicadas en un medio boscoso encontraron una sustancial fuente de ingresos en la explotación de los montes y la venta del carbón vegetal necesario para la transformación del mineral de hierro. En la costa, el clero participó de la actividad pesquera y comercial a través del centenal - uno por ciento de las ganancias de la pesca y el comercio- ${ }^{27}$. De la misma manera, se incrementaron los ingresos por derechos adventicios y mandas funerales al crecer la población y su capacidad de gasto.

\footnotetext{
22 Fernández de Pinedo (1974), pp. 153-156.

23 Catalán (2000), pp. 84-87. Este reparto puede variar en otras zonas con presencia de iglesias patrimoniales.

24 Bilbao y Fernández de Pinedo (1984), p. 108, establecen los mínimos de autosuficiencia en 25 fanegas (13,97 hl.) de trigo bruto por familia equivalentes a algo más de 20 fanegas en neto (11,1 hl.).

Bilbao y Fernández de Pinedo (1984), p. 105.

Véase Apéndice 1.

Catalán (2000), pp. 123-140.
} 


\section{CUADRO 1}

PRODUCTO AGRARIO EN EL ÁREA MARÍTIMA (1545-1775). (HI/año)

\begin{tabular}{|c|c|c|c|c|c|c|}
\hline & Cereal & Legumbre & Manzana & Castaña & Vino & Corderos \\
\hline \multicolumn{7}{|c|}{ A la ración entera en 1545} \\
\hline Valle Nervión & 5,16 & 0,82 & 2,26 & 0,13 & 0,15 & 0,46 \\
\hline Arratia-Nervión & 8,68 & 0,14 & 2,70 & 2,35 & - & 2,08 \\
\hline Valle Deba & 5,51 & 1,48 & 5,51 & 2,12 & - & 2,78 \\
\hline Área costera & 8,75 & 0,20 & 4,57 & 0,28 & 0,03 & 0,75 \\
\hline Interior & 6,89 & 0,03 & 3,31 & 0,82 & 0,09 & 0,47 \\
\hline Beneficio entero & 6,85 & 0,51 & 4,04 & 1,02 & 0,05 & 1,26 \\
\hline P.a. por habitante & 2,09 & 0,87 & 0,70 & 0,26 & 0,05 & 0,32 \\
\hline \multicolumn{7}{|c|}{ A la ración entera en 1775} \\
\hline Valle Nervión & 82,15 & 0,59 & 2,63 & 4,06 & 61,07 & 6,28 \\
\hline Arratia-Nervión & 29,71 & 0,52 & 5,13 & 2,47 & 0,31 & 1,48 \\
\hline Valle Deba & 38,31 & 0,32 & 3,38 & 1,51 & 0,02 & 0,88 \\
\hline Área costera & 37,93 & 0,58 & 6,76 & 3,05 & 8,89 & 1,47 \\
\hline Interior & 28,79 & 0,29 & 6,04 & 2,89 & 0,14 & 1,68 \\
\hline Beneficio entero & 43,38 & 0,46 & 4,79 & 2,80 & 14,09 & 1,92 \\
\hline P.a. por habitante & 3,51 & 0,13 & 0,24 & 0,14 & 0,13 & 1,93 \\
\hline Casa excusada & 62,16 & 0,89 & 21,06 & 4,88 & 9,79 & 7,73 \\
\hline
\end{tabular}

Fuente: Elaboración propia. Averiguación de veros valores 1545 y 1771/75.

El crecimiento agrario, iniciado en el primer tercio del siglo XVI, continuó con mayor o menor intensidad hasta 1580. La ruptura del eje comercial Burgos-Flandes provocó una desestructuración de la economía vasca y una profunda crisis en los sectores secundario y terciario. Como compensación al desabastecimiento de cereal y a la pérdida de empleos, el agro vasco se embarcó en un proceso de crecimiento extensivo - roturación de pastos y sustitución de manzanos por tierras de pan llevar- al que pronto le seguiría un cambio en la utilización del suelo con la introducción del maíz ${ }^{28}$. Este, con respecto a otros granos, poseía unos rendimientos comparativamente altos por simiente y superficie, de ahí que acabara desplazando a otros cereales tanto de primavera como de invierno. La intensificación de la agricultura también afectó a otros cultivos que sufrieron incrementos de productividad notables a partir de la segunda mitad del seiscientos: el barbecho prácticamente desapareció y se compensó el posible agotamiento del suelo con una mayor utilización de abo-

28 Bilbao y Fernández de Pinedo (1984), pp. 113-124. 
nos vegetales y la enmienda de suelos arcillosos ${ }^{29}$. Este cambio estructural quedó reflejado en la composición de las casas excusadas y en la distribución porcentual del valor de los diezmos de la ración entera (Apéndice 3$)^{30}$.

La producción media anual de cereal por unidad de explotación se situó en torno a los 62 hectolitros, de los cuales algo más de la mitad correspondía al maíz. Esto suponía que, con respecto a la producción de 1545, la ratio de cereal por habitante se había multiplicado por 1,7 mientras que en el caso del maíz el factor llegaba hasta 3,8.

Para los beneficiados, este incremento de la producción agraria venía acompañado de un inestimable regalo. Las autoridades civiles y eclesiásticas, ante la pobreza y abandono de la iglesia vasca derivada del régimen de patronato, habían establecido que todos los frutos de las nuevas tierras roturadas repercutiesen directamente sobre los ingresos de los clérigos, quedando los derechos de los patrones limitados al dezmatorio original. Además, ante la exigencia de mantener con un mínimo de decoro a clérigos y templos, muchos patrones optaron por sustituir la congrua — cantidad de dinero dada al servidor en concepto de salario- por una proporción de los diezmos. Esto, y el bajo punto de partida, explica las tasas de crecimiento tan altas que experimentaron productos como el maíz o el vino en las carteras beneficiales.

En aquellos lugares donde no se había conseguido el disfrute de los nuevos quebrantes, la situación de los curas seguía siendo precaria: de la documentación parroquial se deduce que para mantener a un clérigo se necesitaban entre ocho y doce casas dezmeras, aunque en 1775 está situación cada vez era más excepcional. Para entonces, la ratio se había reducido al diezmo de 2,5 casas en las zonas de interior y de 1,25 en las de costa. Los beneficiados del valle del Nervión —Bilbao, Abando y Deusto-, al no estar sometidos a patronato, pudieron participar plenamente de una agricultura muy productiva encaminada a los mercados urbanos. Aquí una ración pudo ser cubierta con menos de una casa dezmera ${ }^{31}$.

CUADRO 2

INGRESOS DE LA RACIÓN ENTERA EN LEKEITIO. 1595-1749 (HI/año)

\begin{tabular}{lcccc}
\hline & $\mathbf{1 5 9 1 - 9 5}$ & $\mathbf{1 6 8 5 - 8 9}$ & $\mathbf{1 7 0 0 - 0 4}$ & $\mathbf{1 7 4 5 - 4 9}$ \\
\hline Trigo & 2,26 & 5,91 & 5,94 & 12,18 \\
Maíz & 0,79 & 9,49 & 9,36 & 18,01 \\
Manzanas & 10,50 & 11,96 & 7,33 & 3,38 \\
\hline
\end{tabular}

Fuente: 1591-95: ACC, leg 2.219; 1685 a 1749: Archivo Histórico Eclesiástico de Bizkaia (AHEB), 53001/14-1.

\footnotetext{
29 Bilbao y Fernández de Pinedo (1984), p. 120 y Bringas (2000), p. 42.

30 Se han tomado los indicadores de la casa excusada como referente de producción agraria bruta aunque arrojen un sesgo al alza por ser la mejor casa de cada localidad.

$31 \quad$ Véase Apéndice 2.
} 
CUADRO 3

TASAS DE CRECIMIENTO Y FACTOR DE MULTIPLICACIÓN DEL PRODUCTO AGRARIO EN EL ÁREA MARÍTIMA. 1545-1775

\begin{tabular}{lcccc}
\hline & \multicolumn{2}{c}{ Tasas de crecimiento medio anual. } & \multicolumn{2}{c}{$\begin{array}{c}\text { Factor de multiplicación. } \\
\text { 1545-1775 }\end{array}$} \\
\cline { 2 - 5 } & $\begin{array}{c}\text { Producto agrario } \\
\text { por habitante }\end{array}$ & $\begin{array}{c}\text { Producto agrario } \\
\text { por beneficio } \\
\text { entero }\end{array}$ & $\begin{array}{c}\text { Producto agrario } \\
\text { por habitante }\end{array}$ & $\begin{array}{c}\text { Producto agrario } \\
\text { por beneficio } \\
\text { entero }\end{array}$ \\
\hline Valle Nervión & $-0,28$ & 0,41 & 0,61 & 17,67 \\
Arratia-Nervión & 0,26 & 0,28 & 2,56 & 2,75 \\
Área costera & 0,15 & 0,32 & 1,51 & 3,91 \\
Valle Deba & 0,11 & 0,30 & 1,34 & 3,15 \\
Interior & $-0,07$ & 0,31 & 0,86 & 3,42 \\
\hline Zona marítima & $\mathbf{0 , 0 2}$ & $\mathbf{0 , 3 5}$ & $\mathbf{1 , 0 5}$ & $\mathbf{5 , 2 5}$ \\
\hline
\end{tabular}

Fuente: Cálculos realizados sobre los datos del Apéndice 2.

Como se puede ver en el Cuadro 3, el producto agrario de los clérigos se multiplicó por 5,25, mientras que el de los habitantes apenas arrojaba un factor de 1,05. A pesar del indudable desarrollo agrícola, éste seguía siendo insuficiente para alimentar a una población que se dedicaba mayoritariamente al comercio, la pesca o la industria. Las tasas medias de crecimiento anual arrojan valores negativos o cercanos al estancamiento en las áreas comerciales — valle del Nervión- e industriales — valle del Deba— donde la población creció muy por encima de la producción; el interior tampoco fue capaz de superar los niveles del siglo XVI, debido a la naturaleza abrupta del suelo; mientras que en la zona costera, la ratio de producción por habitante superaba la media comarcal al haberse desarrollado un cuasi monocultivo del maíz.

\subsection{La zona cerealista}

Atravesando los puertos de Orduña, Barazar y Altube se inicia un cambio de paisaje llamativo. El clima se continentaliza, domina el cereal en los campos y las viviendas se agrupan en torno a la iglesia, en contraste con el caserío disperso de la zona marítima. Aquí el producto estrella era el trigo, cultivado con el sistema de año y vez, complementado por los cereales forrajeros, indispensables en una zona carente de pastos naturales. Esta estructura genérica del campo alavés, precisa de ciertas matizaciones comarcales: en el siglo XVI, la Llanada se consolidó como la zona productora de grano con una renta anual de 11,96 hectolitros por habitante, seguida de 
los Valles Alaveses y la comarca de Miranda de Ebro; mientras, las estribaciones del Gorbea y la Montaña Alavesa se especializaron en cereales menores — cebada, avena, yero, rica y alholva-. A diferencia del área marítima, las familias alavesas superaban con holgura los mínimos de suficiencia lo que las convertía en excedentarias de grano ${ }^{32}$.

En Álava, la presencia de iglesias de patronato era testimonial lo que implicaba, de entrada, un mayor nivel de producto agrario para los clérigos que el que hemos visto para sus colegas vizcaínos y guipuzcoanos. Además, no solo percibían el diezmo íntegro sino que en lugar del tercio pagaban una cantidad fija de trigo y cebada -tasaciones de Álava - por lo que sus ingresos fueron entre un 25 y un 30\% superiores de lo que hubieran sido de haber estado totalmente sometidos a la jurisdicción episcopal.

En el conjunto de la región, los mejores indicadores por clérigo se situaban en la Montaña y los pueblos del entorno mirandés, ya en Burgos. Pero no nos llevemos a engaño, la comarca de la Montaña estaba escasamente poblada y sus parroquias eran servidas por un beneficiado, a lo sumo dos. Por su parte, las iglesias de Miranda de Ebro constituían un caso singular, ya que su contribución al subsidio y excusado se realizaba de forma alternativa: un año con el arzobispado de Burgos y otro con el de Calahorra y La Calzada, por lo que solo manejamos información referida a los años de administración calagurritana, es decir la mitad del quinquenio. Sin lugar a dudas, la Llanada, mayor productora de cereal, era la que podía mantener a un abultado número de clérigos, lo que implicaba una renta media por beneficiado inferior que las de zonas menos densamente pobladas.

En el quinientos, una ración entera obtenía 25,40 hectolitros anuales en concepto de diezmo; una cantidad que se sitúa en el punto medio de la diócesis y que permitió a los clérigos obtener amplios excedentes comercializables y mantenerse con holgura y dignidad. Aunque el producto agrario que le correspondía a un beneficiado tipo era tres veces y media superior al de un feligrés, en la práctica la distancia era mayor puesto que los ingresos de los clérigos eran netos, mientras que las familias debían descontar lo necesario para sementera, diezmo, impuestos o renta de la tierra: unos 3 hectolitros anuales ${ }^{33}$. Para unos y otros, los mínimos de autosuficiencia se fueron alejando durante el siglo XVI, al aumentar los niveles de renta en torno al $25 \%$, estimulados por el alza de los precios y la demanda de cereal en las áreas deficitarias ${ }^{34}$.

\footnotetext{
$32 \quad$ Véase Apéndice 2.

33 A diferencia de lo que sucede en el área marítima donde el 50\% de los campesinos son pequeños propietarios, en Álava solo el 25\% eran dueños de las tierras que trabajaban. Fernández de Pinedo (1974), p. 261.

$34 \quad$ Bilbao y Fernández de Pinedo (1984), p. 107.
} 


\section{CUADRO 4}

PRODUCTO AGRARIO EN LA ZONA CEREALISTA (1545-1775). (HI/año)

\begin{tabular}{|c|c|c|c|c|c|c|}
\hline & Trigo & $\begin{array}{c}\text { Otros } \\
\text { cereales }\end{array}$ & Total cereal & Legumbre & Vino & Corderos \\
\hline \multicolumn{7}{|c|}{ A la ración entera en 1545} \\
\hline Gorbea & 11,08 & 5,83 & 16,91 & 0,16 & 0,15 & 0,97 \\
\hline Montaña & 15,99 & 4,83 & 20,83 & 1,21 & - & 1,48 \\
\hline Llanada & 20,32 & 14,33 & 34,65 & 0,33 & 19,40 & 2,20 \\
\hline Valle Ebro & 8,97 & 6,46 & 15,42 & 0,11 & - & 1,23 \\
\hline Valles alaveses & 10,76 & 5,49 & 16,25 & 0,68 & 0,91 & 3,22 \\
\hline Ración entera & 13,42 & 7,39 & 20,81 & 0,50 & 4,09 & 1,82 \\
\hline P.a. por habitante & 3,65 & 1,60 & 5,25 & 1,87 & 0,60 & 0,31 \\
\hline \multicolumn{7}{|c|}{ A la ración entera en 1775} \\
\hline Gorbea & 39,37 & 44,41 & 83,77 & 6,62 & - & 0,27 \\
\hline Montaña & 20,72 & 15,47 & 36,19 & 0,51 & - & 0,45 \\
\hline Llanada & 9,93 & 15,61 & 25,54 & 0,80 & 7,99 & 0,78 \\
\hline Valle Ebro & 29,38 & 32,82 & 62,20 & 2,17 & - & - \\
\hline Valles alaveses & 26,01 & 26,53 & 52,53 & 1,29 & 0,23 & 0,54 \\
\hline Ración entera & 25,08 & 26,97 & 52,05 & 2,28 & 1,64 & 0,41 \\
\hline P.a. por habitante & 5,72 & 4,99 & 10,71 & 0,27 & 0,24 & 0,60 \\
\hline Casa excusada & 59,93 & 67,11 & 127,04 & 6,00 & 1,83 & 4,07 \\
\hline
\end{tabular}

Fuente: Elaboración propia. Averiguación de veros valores 1545 y 1771/75.

A finales del quinientos, la ruptura de los circuitos comerciales afectó a la demanda de grano de las provincias costeras, llevando al campo alavés a una profunda crisis agravada por la inestabilidad de las cosechas y los precios. La depresión provocó un retroceso demográfico considerable que se tradujo en una manifiesta incapacidad para mantener los mismos efectivos parroquiales que en las épocas de bonanza económica. El abuso de las iglesias al crear nuevos beneficios, aun sin la renta suficiente, generó una situación insostenible que las autoridades eclesiásticas trataron de mitigar a través de las Constituciones Sinodales y de la reestructuración de los cabildos beneficiales ${ }^{35}$. El resultado fue la reducción del número de raciones en un $38 \%$, con especial incidencia en las iglesias de las faldas del Gorbea y las de los Valles Alaveses, que prácticamente se quedaron con la mitad de efectivos. El reajuste de las plantillas beneficiales favorecería el incremento de la renta cuando la coyuntura agrícola cambiase.

35 Constituciones Sinodales de P. González del Castillo (1621), p. 114 y de Pedro de Lepe (1698), pp. $380-388$. 
CUADRO 5

TASAS DE CRECIMIENTO Y FACTOR DE MULTIPLICACIÓN DEL PRODUCTO AGRARIO EN ÁLAVA. 1545-1775

\begin{tabular}{lcccc}
\hline & \multicolumn{2}{c}{$\begin{array}{c}\text { Tasas de crecimiento medio anual. } \\
\text { 15475 }\end{array}$} & \multicolumn{2}{c}{$\begin{array}{c}\text { Factor de multiplicación. } \\
\text { 1545-1775 }\end{array}$} \\
\cline { 2 - 5 } & $\begin{array}{c}\text { Producto agrario } \\
\text { por habitante }\end{array}$ & $\begin{array}{c}\text { Producto agrario } \\
\text { por beneficio } \\
\text { entero }\end{array}$ & $\begin{array}{c}\text { Producto agrario } \\
\text { por habitante }\end{array}$ & $\begin{array}{c}\text { Producto agrario } \\
\text { por beneficio } \\
\text { entero }\end{array}$ \\
\hline Llanada & 0,01 & 0,35 & 1,10 & 5,25 \\
Montaña & 0,02 & 0,17 & 1,11 & 1,67 \\
Valle Ebro & 0,08 & $-0,25$ & 1,27 & 0,63 \\
Valles alaveses & 0,17 & 0,29 & 1,77 & 3,03 \\
Gorbea & 0,27 & 0,33 & 3,19 & 4,14 \\
Álava & 0,11 & 0,24 & 1,45 & 2,20 \\
\hline
\end{tabular}

Fuente: Cálculos realizados sobre los datos del Apéndice 2.

A partir de 1730, se inició la recuperación en el área cerealista basada en el incremento de la superficie cultivada y en una probable progresión del sistema de cultivo en rotación trienal ${ }^{36}$. El motor del cambio hay que buscarlo en las regiones vecinas: la especialización vinícola de La Rioja, propició el necesario abastecimiento de cereal en las zonas excedentarias; además, la necesidad de transporte para los caldos riojanos estimuló necesariamente la producción de piensos para caballerías. El desarrollo agrícola fue responsable de una recuperación demográfica, aunque sin alcanzar los niveles de las anteriores épocas de expansión. La menor densidad de población combinada con el crecimiento agrícola permitió un aumento de la renta por habitante de en torno al 30,26\%, basado en el retroceso del trigo y el viñedo a favor de los cereales forrajeros y las legumbres ${ }^{37}$.

¿Cómo afectaron estas transformaciones a los clérigos alaveses? El auge agrícola del XVIII permitió que, con respecto a 1545, las carteras beneficiales se multiplicaran por 2,2 y en el caso de La Llanada hasta por 5,25. La reestructuración beneficial había equilibrado el número de eclesiásticos de cada parroquia haciéndose, en general, más llevadera la manutención de los efectivos de cada iglesia: en Álava tan solo se necesitaba el diezmo de algo más de dos unidades de explotación para cubrir una ración entera; ratio que disminuía hasta 1,3 en el caso de la Llanada

Bilbao y Fernández de Pinedo (1984), p. 156.

Bilbao y Fernández de Pinedo (1984), p. 153, tomando como referencia datos de 1588-92 cifran el crecimiento del P.A.B. por vecino en un $37,03 \%$, lo que permite equiparar esta región con las regiones cerealistas más dinámicas de Europa. 
donde se concentraban las explotaciones más productivas y mayor número de vecinos. Por el contrario, en la Montaña alavesa el estancamiento de la producción hizo necesario el diezmo de más de tres casas para poder mantener la renta de uno de sus sacerdotes.

\subsection{La Rioja: tierra de vino}

La actual comunidad de La Rioja, al sur del Obispado, presentaba una estructura agraria basada en una división interregional del trabajo, lo que la alejaba de las zonas específicamente cerealistas. En la Rioja Alavesa, la proximidad a los mercados urbanos del País Vasco y la ventaja fiscal propiciaron el desarrollo de la producción vinícola; por su parte, el rioja castellano buscó su mercado en las prósperas ciudades del interior, en el abastecimiento de las rutas laneras y de los peregrinos del camino francés; la Rioja Baja -Arnedo, Calahorra y Alfaro-, más próxima a Zaragoza que a Bilbao, aún estando magníficamente dotada para la producción de caldos, quedaba muy por detrás de las otras zonas vinateras precisamente por su lejanía de los mercados más dinámicos. El fuerte desarrollo del viñedo, y la utilización masiva del terrazgo en el cultivo de cepas, originó un gran déficit de granos, tanto para consumo humano como animal, que fue suplido por la comercialización desde Álava y las zonas cerealistas de La Rioja. Paralelamente, la sierra se especializó en ganadería trashumante y en la elaboración de textiles dirigidos básicamente al mercado regional. La intensificación de los intercambios estimuló la demanda de servicios de transporte que necesitaban de forraje para alimentar a las caballerías.

Esta diversidad productiva proporcionó a la Iglesia unos ingresos considerables en concepto de diezmo, aunque no repercutieron como cabría esperar en la economía de los cabildos parroquiales. En primer lugar, el clero riojano estuvo sometido a mayor presión fiscal que la de sus colegas vascos ya que todos debían ceder la tercera o cuarta parte de su producto agrario a las iglesias catedrales; las tierras de los monasterios, que estaban total o parcialmente exentas de diezmo, eran mucho más numerosas que en el norte de la diócesis; el pago del excusado era más gravoso en las parroquias ricas ya que el valor de la producción de la casa mayor dezmera era considerable; y por último, existían toda una serie de deberes de pago, derivados del ejercicio jurisdiccional y de la difusión de la doctrina, que se abonaban en las especies más valoradas. Por otra parte, las iglesias riojanas arrojaban la mayor ratio de beneficiados por parroquia, lo que se tradujo en una menor porción de producto agrario per cápita. Aún con todo, los clérigos riojanos ocuparon las primeras posiciones en el ranking beneficial encabezados por los curas de la Rioja Alta que percibían de media 65,59 hectolitros en concepto de 
diezmo (Apéndice 4). Sin duda, esta cantidad llegó a ser muy superior en la segunda mitad del siglo XVI ya que, desde la averiguación de 1545, el producto agrario bruto se había incrementado en torno al $40 \%{ }^{38}$.

A partir de la década de 1570 se conjugaron varios factores que provocarían una profunda depresión: el declive del comercio de la lana afectó tanto a las economías ganaderas como al entorno de Nájera, que se había convertido en uno de los centros más reputados en la negociación de este producto ${ }^{39}$; el declinar del Camino de Santiago llevó a languidecer muchas de las actividades que habían florecido a su paso; los alimentos dejaron de crecer por encima de la población provocando crisis de subsistencias, a las que se uniría la peste en 1598-1601. La crisis agraria tocó fondo durante 1630-31 dejando una grave secuela demográfica: La Rioja había perdido el $30 \%$ de su población ${ }^{40}$. A partir de aquí, el campo riojano apostó por la sustitución del trigo por la cebada, el abandono del viñedo o la expansión del mismo en función de las condiciones de comercialización del producto.

Al igual que sucedió en Álava, el descenso de la producción agraria impuso, por parte de las autoridades eclesiásticas, un reajuste de las plantillas parroquiales: el descenso del número de beneficiados se sitúo en torno al $23,28 \%$ en el área vinatera y al $19 \%$ en las serranías ${ }^{41}$, lo que debió facilitar el mantenimiento de las congruas beneficiales en niveles similares a los del siglo XVI.

Paralelamente, la fundación de capellanías conoció una época dorada en todos los confines de la monarquía hispana. En el arciprestazgo de Nágera el 63,59\% de las capellanías, que a finales del XVIII seguían en activo, se habían fundado en el siglo anterior; eso sí, con una dotación económica escasa. Lo que nos interesa de este dato es que más de la mitad fueron promovidas por eclesiásticos, o sus familiares, con la clara intención de complementar las rentas de los clérigos más modestos. Al no exigir residencia estos las acumulaban, llegando a suponer incrementos sobre su renta de hasta un $60 \%$. Tampoco hay que pasar por alto el hecho de que el aumento de fundaciones implicaba una acumulación de capital previa: a pesar de la crisis agrícola, los eclesiásticos pudieron disponer de bienes y capitales que utilizaron para garantizar el decoro suficiente a los clérigos con los que les unían lazos de parentesco o vecindad.

La recuperación económica llegó en el siglo XVII de la mano de la reactivación de la demanda vasca, aunque no lo hizo al mismo tiempo ni de la misma manera. La

\footnotetext{
38 Ibáñez y Alonso (1996), pp. 216-218.

39 Diago Hernando (2000), p. 69.

40 Gurría García (2004), p. 71.

41 Véase Apéndice 1. Ibáñez (1999), p. 274, usando como fuente el Catastro de la Ensenada, señala un aumento de clérigos en La Rioja de un $12 \%$. Estos datos incluyen al conjunto de personas, que no de raciones que es la base del reparto económico dentro de cada iglesia.
} 
CUADRO 6

PRODUCTO AGRARIO EN LA RIOJA. 1545-1775 (HI/año)

\begin{tabular}{|c|c|c|c|c|c|c|c|}
\hline & Trigo & $\begin{array}{l}\text { Otros } \\
\text { cereales }\end{array}$ & $\begin{array}{l}\text { Total } \\
\text { cereal }\end{array}$ & Legumbres & Vino & Olivas & Corderos \\
\hline \multicolumn{8}{|c|}{ A la ración entera en 1545} \\
\hline \multicolumn{8}{|l|}{ Sierra } \\
\hline Camero viejo & 10,46 & 2,67 & 13,13 & 0,44 & - & - & 11,12 \\
\hline Yanguas (Soria) & 22,26 & 6,92 & 29,18 & - & - & - & 12,52 \\
\hline \multicolumn{8}{|l|}{ Viñedo } \\
\hline Rioja alavesa & 14,59 & 22,58 & 37,17 & 0,08 & 13,77 & - & 3,90 \\
\hline Rioja alta & 18,49 & 20,49 & 38,98 & 0,19 & 26,38 & 0,04 & 5,34 \\
\hline Rioja baja & 16,60 & 12,19 & 28,79 & - & 6,85 & - & 11,07 \\
\hline \multicolumn{8}{|l|}{ Mixta } \\
\hline Mixta olivar & 16,55 & 7,98 & 24,53 & - & 3,48 & - & 8,69 \\
\hline Mixta cebada & 13,48 & 13,76 & 27,24 & 0,06 & 2,52 & - & 2,96 \\
\hline Sin viñedo & 12,73 & 15,07 & 27,80 & 0,06 & - & - & 4,89 \\
\hline \multicolumn{8}{|c|}{ Por habitante en 1545} \\
\hline Sierra & 2,01 & 0,61 & 2,43 & 0,61 & 0,07 & - & 0,96 \\
\hline Viñedo & 2,42 & 1,56 & 3,98 & 1,57 & 2,90 & 0,01 & 0,75 \\
\hline Mixta & 3,12 & 3,42 & 6,54 & 3,43 & 0,59 & - & 0,66 \\
\hline Sin viñedo & 3,07 & 2,18 & 5,25 & 2,19 & - & - & 0,71 \\
\hline \multicolumn{8}{|c|}{ A la ración entera en 1775} \\
\hline \multicolumn{8}{|l|}{ Sierra } \\
\hline Camero viejo & 20,04 & 12,74 & 32,78 & 0,44 & - & - & 11,12 \\
\hline Yanguas (Soria) & 16,26 & 45,43 & 61,69 & 0,37 & - & - & 19,35 \\
\hline \multicolumn{8}{|l|}{ Viñedo } \\
\hline Rioja alavesa & 23,01 & 21,61 & 44,61 & 0,87 & 127,28 & 4,02 & 6,22 \\
\hline Rioja alta & 14,84 & 23,20 & 38,04 & 1,97 & 50,34 & 0,06 & 5,55 \\
\hline Rioja baja & 21,67 & 41,00 & 62,67 & 0,66 & 31,98 & 6,63 & 13,79 \\
\hline \multicolumn{8}{|l|}{ Mixta } \\
\hline Mixta olivar & 24,39 & 31,66 & 56,05 & 2,58 & 23,02 & 7,17 & 10,37 \\
\hline Mixta cebada & 21,11 & 39,03 & 60,14 & 8,73 & 2,95 & - & 9,19 \\
\hline Sin viñedo & 12,22 & 31,46 & 43,68 & 7,65 & - & - & 10,14 \\
\hline \multicolumn{8}{|c|}{ Por habitante en 1775} \\
\hline Sierra & 2,28 & 7,68 & 9,96 & 0,12 & - & - & 5,11 \\
\hline Viñedo & 2,61 & 4,13 & 6,68 & 0,26 & 5,34 & 0,48 & 1,13 \\
\hline Mixta & 4,33 & 8,26 & 12,59 & 0,35 & 1,12 & 0,90 & 1,29 \\
\hline Sin viñedo & 2,36 & 7,05 & 9,41 & 0,13 & - & 0,20 & 2,20 \\
\hline \multicolumn{8}{|c|}{ Producción anual de las casas excusadas en 1775} \\
\hline Sierra & 61,25 & 47,86 & 101,35 & 1,34 & - & - & 92,71 \\
\hline Viñedo & 94,74 & 94,66 & 200,64 & 10,70 & 272,42 & 3,83 & 76,93 \\
\hline Mixta & 82,60 & 152,69 & 232,97 & 6,39 & 71,28 & - & 67,50 \\
\hline Sin viñedo & 31,50 & 70,73 & 103,62 & 1,44 & - & - & 36,83 \\
\hline \multicolumn{8}{|c|}{$\begin{array}{l}\text { Fuente: Elaboración propia. Averiguación de veros valores } 1545 \text { y 1771/75. Criterios para la división geográfica en Ibáñez } \\
\text { y Alonso (1996), pp. 212-214. }\end{array}$} \\
\hline Nota: El producto agra & hab & te se ofrece & manera & esglosada debid & que, & & \\
\hline
\end{tabular}


Rioja Alavesa saldría claramente favorecida por su proximidad a los nuevos mercados y la menor presión fiscal que soportaban sus productos. Al igual que sucediera durante el quinientos, el rioja castellano no pudo hacer frente a la competencia de un producto más barato en origen y con menores costes de transporte, pero esta vez carecía de alternativas donde comercializarse. A esto hay que añadir una fuerte desarticulación de las zonas productoras que las llevaba a rivalizar entre sít ${ }^{42}$ y una desaceleración de los precios de los caldos frente a los del cereal a partir de la abolición de la tasa. Las zonas más alejadas del valle optaron por la reducción e incluso abandono del viñedo a favor de la cebada, legumbres, linares u olivos lo que les permitió mantener niveles de renta agraria per cápita superiores a los del área vinícola.

Los datos del Cuadro 7, muestran claramente las diferencias comarcales originadas por una excesiva especialización productiva en el marco de una economía de Antiguo Régimen: las zonas vinícolas castellanas, aun siendo prácticamente idénticas a la alavesa, muestran valores cercanos al estancamiento e incluso negativos; en cambio, las regiones que optaron por cultivos alternativos al trigo o la vid consiguieron un crecimiento más activo. En la serranía, el cambio de estructura afectó de manera diferente a los cabildos de Yanguas que a los de Cameros. Los primeros compartieron características propias de las tierras bajas de Arnedo: desplazamiento del trigo por la cebada, aparición de los cultivos industriales y consolidación de la crianza de corderos churros frente a merinos. Por su parte, Cameros sufrió una transformación importante como consecuencia de la crisis del sector textil y el cierre de

CUADRO 7

TASAS DE CRECIMIENTO Y FACTOR DE MULTIPLICACIÓN DEL PRODUCTO AGRARIO EN LA RIOJA. 1545-1775

\begin{tabular}{lcccc}
\hline & \multicolumn{2}{c}{ Tasas de crecimiento medio anual. } & \multicolumn{2}{c}{$\begin{array}{c}\text { Factor de multiplicación. } \\
\mathbf{1 5 4 5 - 1 7 7 5}\end{array}$} \\
\cline { 2 - 5 } & $\begin{array}{c}\text { Producto agrario } \\
\text { por habitante }\end{array}$ & $\begin{array}{c}\text { Producto agrario } \\
\text { por beneficio } \\
\text { entero }\end{array}$ & $\begin{array}{c}\text { Producto agrario } \\
\text { por habitante }\end{array}$ & $\begin{array}{c}\text { Producto agrario } \\
\text { por beneficio } \\
\text { entero }\end{array}$ \\
\hline Cameros & 0,25 & 0,26 & 2,32 & 2,45 \\
Yanguas (Soria) & 0,32 & 0,23 & 3,90 & 2,11 \\
Rioja Alavesa & 0,29 & 0,31 & 2,93 & 3,46 \\
Rioja Alta & 0,05 & 0,12 & 1,13 & 1,38 \\
Rioja Baja & $-0,08$ & 0,28 & 0,85 & 2,86 \\
Mixta olivar & 0,29 & 0,30 & 3,01 & 3,17 \\
Mixta cebada & 0,11 & 0,25 & 1,34 & 2,41 \\
Sin viñedo & 0,10 & 0,25 & 1,31 & 1,85 \\
\hline
\end{tabular}

Fuente: Cálculos realizados sobre los datos del Apéndice 2.

42 Ibáñez (2002), pp. 47-48. 
los mercados exteriores ${ }^{43}$ : la ganadería trashumante prácticamente se abandonó a favor del ganado estabulado criado en el valle, cuya lana gozaba de gran aceptación por la industria local especializada en tejidos bastos. Las tierras altas se dedicaron a la producción de plantas forrajeras, indispensables en la alimentación del ganado estante, y de ciertas especies utilizadas en la industria textil, como el cardón.

Tras un siglo de crecimiento, la imagen que ofrecen las averiguaciones de veros valores de 1771-75 es bastante elocuente: el clero parroquial riojano percibía un 45\% más de producto agrario que en el siglo XVI. Aunque los clérigos del área vinatera seguían ostentando las mayores rentas de la diócesis, estas se habían incrementado en menor medida que las del área marítima o cerealista debido al escaso ajuste en las plantillas parroquiales. Los servidores del valle del Ebro fueron superados por los de la Rioja Alavesa que, con 176,78 hectolitros por ración y una valoración monetaria de 4.787 reales, se convirtieron en los mejor pagados del obispado. Para la sociedad riojana, la retribución de un clero tan numeroso supuso una pesada carga: hacía falta el diezmo de 5,8 de las mejores casas para mantener a un cura en propiedad.

\section{La renta agraria de los canónigos: los tercios decimales}

Dentro del área riojana, se debe reseñar de manera especial, la situación de los canónigos de las iglesias catedrales cuya renta agraria procedía de la parte que cedían las parroquias para el mantenimiento de la jerarquía — las tercias - . La distribución de estas no era proporcional ni equitativa.

El cuerpo de canónigos de cada una de las catedrales tenía asignado un número determinado de parroquias y su producto venía a representar un $15 \%$ de la masa decimal del obispado ${ }^{44}$. A los canónigos que componían el cabildo de La Calzada les había correspondido la cuarta parte del diezmo de las iglesias menos productivas, lo que suponía el 66\% del total de sus rentas; mientras que los de Calahorra gestionaban el tercio reglamentario de las suyas, que representaban el $84 \%$ de su retribución.

Los ingresos de la cúpula catedralicia estuvieron afectados tanto por las variaciones coyunturales como por la gestión que varió en función del coste de oportunidad de cada parroquia. Normalmente, aquellas que por proximidad geográfica a la iglesia catedral no presentaban elevados gastos de transporte o bien tuvieron la posibilidad de almacenar durante un tiempo el grano, se administraron directamente ya que la venta de estos frutos en el mercado superaba ampliamente los gastos de almacenamiento y administración. Por el contrario, aquellas que se encontraban más alejadas de la catedral o cuyos productos eran perecederos o necesitaban de elaboración previa — caso del vino o el aceite- conllevaban una serie de gastos de pro-

\footnotetext{
$43 \quad$ Moreno Fernández (1996), pp. 292 y ss.

44 Este porcentaje no está muy alejado de lo que sucede en Galicia donde los canónigos de las distintas iglesias catedrales percibían el 13,1\% de la masa decimal. Rey Castelao (1992), p. 147.
} 
ducción que no siempre eran compensados con la venta del producto al precio oficial. La Iglesia, como gran perceptora de renta agraria, podía negociar condiciones realmente atractivas en la venta de sus productos. A pesar de que los precios de tasa regían para todo el obispado, solo se respetaron sistemáticamente para las especies menores - avena o centeno- mientras que para el trigo, la cebada o el vino no dudaron en contravenirlo si el precio de mercado superaba al legal ${ }^{45}$. Además, en esta esfera de negociación al más alto nivel, las presiones de las oligarquías municipales, especialmente en tiempos de escasez, les llevó a optar por el arrendamiento ante la imposibilidad de infringir la normativa de los precios ${ }^{46}$.

Como se puede ver en el Gráfico 1, al comienzo de la recesión los canónigos consiguieron frenar la caída de sus rentas con un modelo de gestión mixto, en el que combinaron el arrendamiento de los productos que conllevaban cargas más elevadas, o tenían una menor valoración en el mercado, con la administración directa de los cereales mayores, lo que les permitió rentabilizar al máximo la carestía de grano. Esta estrategia fue válida mientras se mantuvieron los circuitos de comercialización y la moneda de vellón guardó paridad con la de plata. Pero, en las últimas décadas del quinientos, los canales de comercialización y distribución de granos, vino o lana

\section{GRÁFICO 1}

INGRESOS DE LOS CANÓNIGOS DEL OBISPADO DE CALAHORRA Y LA CALZADA EN CONCEPTO DE TERCIO DECIMAL

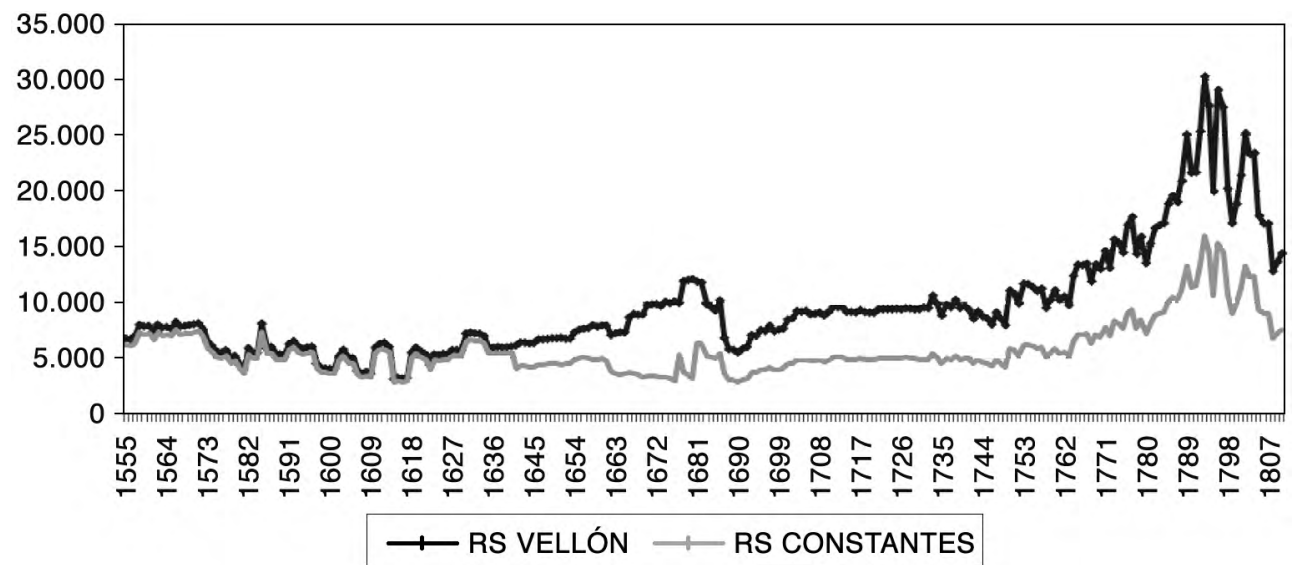

Fuente: Libros de Préstamos y tercias de las iglesias catedrales de Santo Domingo de la Calzada y Calahorra ${ }^{47}$.

45 Este comportamiento es similar al de otras regiones. Feliú (1991), p. 12; Llopis y Jerez (2001), pp. 46-49.

$46 \quad$ Llopis y Jerez (2001), p. 50.

$47 \quad$ Para elaborar este gráfico se ha realizado un indicador del producto agrario percibido en concepto de tercia de los 38 pueblos asignados a los acerbos de los cabildos catedralicios. Los datos se han sometido a un análisis en componentes principales normado corregido con el producto de la desviación típica más la suma de la media. 
se hundieron y con ellos la posibilidad de optimizar el producto de los diezmos. Además, la decisión de monetizar una parte de la deuda con la emisión de una moneda carente de contenido metálico, provocó una fuerte inflación que comprometía la recuperación económica. En este contexto, los canónigos decidieron evitar riesgos y optaron por el arrendamiento, aunque esto implicase una merma en el control de la gestión y cobrar sus rentas en una moneda cada vez más depreciada.

En el primer tercio del siglo XVIII, la estabilidad monetaria y la recuperación agrícola propiciaron la vuelta progresiva a la administración directa, al principio en las parroquias más prósperas y poco a poco en las demás. A partir de 1760, la abolición de la tasa provocó un fortísimo incremento en el precio de los principales productos con el consiguiente enriquecimiento de los grandes perceptores de diezmos.

\section{El ranking beneficial}

Como hemos podido constatar, la capacidad de gestión de la masa decimal quedaba limitada a los grandes perceptores ya que los pequeños cabildos parroquiales delegaban en los representantes del obispado la comercialización de sus derechos, y por lo tanto estaban supeditados a la gestión de aquellos. La valoración monetaria de las diferentes especies que componían el ingreso decimal, aun siendo a precios de tasa, corroboran la estructura del ingreso que hemos trazado para cada beneficiado así como el cambio estructural producido entre los siglos XVI al XVIII (Apéndice 3). En el quinientos, los ingresos decimales del obispado se componían fundamentalmente de cereal y vino, excepto en las parroquias del área marítima donde los clérigos percibían cerca de la mitad de sus rentas en dinero, a través de las cuotas de los patrones y la comercialización de menucias en los mercados urbanos. A finales del siglo XVIII, la estructura agraria del obispado se había modificado sensiblemente: el maíz dominaba en el área holohúmeda, habiéndose reducido el peso del aporte monetario de los clérigos; en La Rioja, la cebada había sustituido al trigo como cereal principal en la alternancia de cultivos, siendo la gran protagonista del cambio; la vid se había convertido en monocultivo en la mayoría de las localidades de la ribera alta del Ebro y había experimentado un notable avance en los valles orientales donde la producción de caldos llegó a representar entre el 30\% y el 50\% del producto agrario; por último, aquellos lugares que tenían una peor dotación de suelo y se encontraban alejados de los centros de comercialización, abandonaron por completo la vitivinicultura ante la imposibilidad de competir con la gran zona productora.

La situación económica de los clérigos del obispado fue bien dispar debido a la diversidad económica y social de las parroquias en las que prestaban sus servicios. En todas las zonas, con excepción quizá de la de patronato de laicos, la renta agraria de un beneficio entero estuvo por encima de la sus feligreses, distancia que se acrecentó en el setecientos debido al ajuste de servidores por parroquia y al aumento de la producción. 
Desde el principio, las autoridades eclesiásticas se preocuparon por establecer el valor mínimo de una ración, habida cuenta del estado precario en que se encontraban la mayoría de los servidores del área cantábrica. A comienzos del siglo XVI, se estimó que la renta mínima con la que un sacerdote podía vivir ascendía a 353 reales anuales, cantidad que se ampliaría a 880 reales de vellón en 1698 y a 2.000 en $1770^{48}$. Estas cantidades solo tenían en cuenta el valor de los diezmos ya que, como se ha visto, servían para determinar el número de eclesiásticos que podía mantener una población. Pero sin duda, los ingresos variables, procedentes del ejercicio de la labor pastoral, fueron los que les permitieron mantener un nivel de vida acorde con su dignidad, máxime si se tiene en cuenta que el importe de una misa de difuntos ordinaria era el doble de lo cobrado por un obrero agrícola ${ }^{49}$.

La valoración monetaria de la renta media del clero parroquial (Apéndice 4) depara más de una sorpresa: en 1545, solo los clérigos del área del viñedo y los de la marítima superaban, con el único aporte del diezmo, el mínimo establecido. El caso de los riojanos no es llamativo, puesto que percibían la mayor cantidad de producto agrario, pero sí el de los vascos, que se situaban en los últimos puestos de la tabla con un promedio de 12,47 hectolitros cada uno. Como sabemos, la renta de estos sacerdotes dependía de la voluntad del propietario de la iglesia: unas veces percibían el diezmo de alguna de las casas de la parroquia; otras cobraban una cantidad fija que les compensase del diezmo al que no tenían derecho y, en este caso, era frecuente que se les cediera íntegra la percepción de manzanas — con las que elaboraban sidra- y menucias que comercializaban en los mercados urbanos muy dinámicos en esta zona; de ahí, la alta valoración monetaria de estos servidores. En las sierras y zonas del interior, el producto del diezmo tampoco cubría por sí solo las necesidades básicas de los clérigos que dependían de los ingresos de misas y funerales para completar su estipendio. El crecimiento agrario de la segunda mitad de la centuria incrementaría, sin duda, tanto la renta decimal como los derechos adventicios que percibían de una feligresía cada vez más numerosa.

La crisis del XVII cambió la correlación de fuerzas gracias al ajuste de las plantillas beneficiales y a un cambio en la estructura de los cultivos. Todo ello permitió que, ya en el setecientos, la inmensa mayoría de los servidores de la diócesis llegaran con holgura a los 2.000 reales en que se había fijado el mínimo de renta. En el ranking que hemos establecido, se aprecia un proceso de convergencia entre los beneficiados con una dotación agrícola menor y los que pudieron rentabilizar al máximo los ingresos decimales: en la parte alta de la tabla se encuentran los de la Rioja Alavesa que desplazaron a sus colegas castellanos, gracias a las mejores posibilidades de comercialización de sus vinos; en el otro extremo, los que sirven en áreas donde el viñedo ha desaparecido, en las serranías o en iglesias de patronato,

\footnotetext{
$48 \quad$ Ibáñez (1999), p. 284.

$49 \quad$ Morgado (2000), p. 92.
} 
ya que, a pesar de haber mejorado sensiblemente el aporte en especie, la valoración monetaria de estos productos no alcanzó a cubrir las necesidades mínimas de este colectivo; y por último, en una franja intermedia — en torno a 2.000 reales-, aquellos que, aun gozando del diezmo íntegro, habían visto sustituir el trigo por la cebada, de menor valoración monetaria.

En líneas generales, estos valores se muestran coincidentes con los que aporta Ofelia Rey para los obispados gallegos por las mismas fechas: en la parte alta de la tabla, los párrocos de la Rioja Alavesa superarían en casi mil reales a los del obispado de Tuy (3.543 reales) y, en la parte baja, los servidores de las iglesias del Gorbea casi duplicarían la renta decimal de los del obispado de Lugo ${ }^{50}$. Barrio Gozalo cifra la renta bruta de la mitad del bajo clero parroquial segoviano, en torno a los 3.000 reales anuales, mientras que sólo el 23\% de ellos superaban los 6.000 reales $^{51}$; ingresos que contemplan además de los diezmos, los derechos adventicios y las rentas dotales que vienen a suponer grosso modo el 50\% del total. Si aplicamos este porcentaje a la renta de los beneficiados calagurritanos se obtienen valores similares e incluso muy superiores al de los segovianos.

En cualquier caso, parece demostrado por la historiografía que la mayor parte del bajo clero no podía mantener su nivel de vida con el único aporte del diezmo , ya que este no bastaba para cubrir los 5.000 o 6.000 reales anuales de gasto que necesitaban para llevar una vida moderada ${ }^{52}$. Para ello, era imprescindible contar con el aporte de las misas y limosnas y, en la medida que las constituciones sinodales lo permitieran, la acumulación de varios beneficios o la posesión de alguna capellanía. El "pluriempleo" resultaba vital para aquellos que únicamente tenían derecho a una porción de la ración entera: en Calahorra solo el 53\% de los beneficiados percibían la renta íntegra; el 19\% cobraban la mitad; el 9\% la cuarta parte, y el resto dependía del salario que le proporcionaba el cabildo. Para estos, su nivel de vida no difería demasiado del de las clases populares.

\section{Conclusiones}

El análisis del bajo clero calagurritano nos muestra una multiplicidad de situaciones en las que están presentes la diversidad regional, la gradación jerárquica, la pervi-

50 Rey Castelao (1992), p. 149. Debemos señalar que las rentas que aquí se muestran corresponden a las de un beneficiado entero por lo que hay que añadir la cuota fija de trigo y cebada que llevan en Álava o la sexta parte de la cantidad señalada en La Rioja. En cualquier caso, son ingresos superiores a los citados.

51 Barrio Gozalo (1982), p. 426. Estos salarios eran equiparables al de los funcionarios reales y señoriales del mundo rural.

52 Los gastos más importantes de un párroco provienen de la alimentación, el vestido y personal de servicio que ascendía en la Segovia del setecientos a 5.000 reales según Barrio Gozalo (1982), pp. $433-435$ y en Cádiz a unos 6.600. Morgado (2000), p. 92. 
vencia de usos y derechos feudales o el ajuste del organigrama parroquial ante una coyuntura concreta.

Desde una perspectiva estamental, cualquier eclesiástico podía considerarse privilegiado puesto que su participación en el excedente agrario le situaba entre los perceptores de renta. La Iglesia, al reproducir las relaciones de dependencia que regían la sociedad civil, generó una fuerte desigualdad interna cuyos límites son difíciles de definir. Más allá del valor intrínseco de la renta eclesiástica, la frontera entre el alto y bajo clero parece que estuvo determinada por la capacidad de gestión y la amplitud del territorio abarcado: únicamente la percepción de parte de la masa decimal de territorios extensos permitía salvar la desigualdad regional originada por la diversidad del medio físico, así como acumular la suficiente cantidad de producto que les permitiese negociar las condiciones más ventajosas de explotación y comercialización. El clero parroquial, con unos márgenes de actuación mucho más estrechos, mantuvo niveles de renta superiores a los de sus feligreses aunque claramente insuficientes para sufragar los gastos derivados de su posición social. En este contexto, los ingresos procedentes del ejercicio pastoral se convirtieron en imprescindibles generando un nuevo foco de desigualdad: el incremento de la demanda de oficios religiosos debía cubrirse sin alterar las relaciones de fuerza de cada parroquia; esto alentó la creación, por un lado, de un grupo de clérigos deficientemente remunerados y, por otro, de un clero privado financiado por particulares aunque sin derecho a la masa decimal.

\section{Bibliografía}

BARREIRO MALLÓN, Baudilio (2000): “La producción agraria gallega: estructura y crisis durante la segunda mitad del siglo XVI", en USUNÁRIZ GARAYOA, Jesús M. a (ed.), Historia y Humanismo. Estudios en honor del profesor Dr. D. Valentín Vázquez de Prada. II Historia Económica, Pamplona, EUNSA.

BARRIO GOZALO, Maximiliano (1982): Estudio socio-económico de la Iglesia de Segovia en el siglo XVIII, Segovia, Caja de Ahorros y Monte de Piedad de Segovia.

BILBAO BILBAO, Luis M. a (1982): “El clero y el régimen patronal de las Iglesias del País Vasco, en 1616, ante el juicio de su Obispo. Glosa a un documento inédito", Scriptorium Victoriense, 29, pp. 107-126.

BILBAO, Luis M. ${ }^{a}$ y FERNÁNDEZ DE PINEDO, Emiliano (1984): "La producción agrícola en el País Vasco (1537-1850)", Eusko Ikaskuntza. Cuadernos de Sección. Historia-Geografía, 2, pp. 85-196.

BRINGAS GUTIÉRREZ, Miguel Ángel (2000): La producción y la productividad de los factores en la agricultura española, 1752-1935, Madrid, Banco de España.

CANALES, Esteban (1985): “Diezmos y revolución burguesa en España”, en GARCÍA SANZ, Ángel y GARRABOU, Ramón (eds.), Historia agraria de la España 
contemporánea. 1. Cambio social y nuevas formas de propiedad (1800-1850), Crítica, Barcelona, pp. 245-274.

CARRION ARREGUI, Ignacio (1996): "Los antiguos pesos y medidas guipuzcoanos", Vasconia, 24, pp. 59-69.

CATALÁN MARTÍNEZ, Elena (2000): El precio del purgatorio. Los ingresos del clero vasco en la Edad Moderna, Bilbao, Universidad del País Vasco.

-(2004): "El derecho de patronato y el régimen beneficial de la iglesia española en la Edad Moderna", Hispania sacra, n. ${ }^{\circ} 113$, pp. 135-168.

DIAGO HERNANDO, Máximo (2000): “El papel de la lana en las relaciones económicas entre Soria y las villas pañeras cameranas en los siglos XVI y XVII", Berceo, 138, pp. 61-90.

DÍAZ DE DURANA, José Ramón (1998): "Patronatos, patronos, clérigos y parroquianos. Los derechos de patronazgo sobre los monasterios e Iglesias como fuente de renta e instrumento de control y dominación de los Parientes Mayores Guipuzcoanos (siglos XIV al XVI)", Hispania Sacra, Vol. 50, n. ${ }^{\circ} 102$ La época de Felipe II y los Austrias, pp. 467-507.

DOMÍNGUEZ ORTIZ, Antonio (1979): Las clases privilegiadas en el Antiguo Régimen, Madrid, Itsmo.

FELIÚ MONFORT, Gaspar (1991): Precios y salarios en la Cataluña moderna. Vol. I. Los alimentos, Madrid, Banco de España, Estudios de Historia económica, 21, pp. 7-195.

FERNÁNDEZ DE PINEDO, Emiliano (1974): Crecimiento económico y transformaciones sociales del País Vasco (1100-1850), Madrid, Siglo XXI.

-(2000): "Prólogo" a CATALÁN MARTÍNEZ, Elena, El precio del purgatorio. Los ingresos del clero vasco en la Edad Moderna, Bilbao, Universidad del País Vasco, pp. 19-22.

FONSECA MONTES, Josué (1992): El clero en Cantabria en la Edad Moderna. Un estudio sobre la implantación de la Contrarreforma en el Norte de España, Santander, Servicio de Publicaciones de la Universidad de Cantabria.

GONZÁlEZ, Tomás (1829): Censo de población de las provincias y partidos de la Corona de Castilla en el siglo XVI, Madrid.

GURRIA GARCÍA, Pedro (2004): “Dinámicas demográficas de la Rioja a partir de series de bautismos, 1580-1900", en Áreas, Revista de Ciencias Sociales, n. ${ }^{\circ} 24$, pp. 67-82.

IBÁÑEZ RODRÍGUEZ, Santiago (1999): El pan de Dios y el Pan de los Hombres. Diezmos, primicias y rentas en la diócesis de Calahorra (ss. XVI-XVIII), Logroño, Universidad de La Rioja.

—(2002): "La consolidación del vino de Rioja en el siglo XVII", Historia Agraria, 26, pp. 33-68.

IBÁÑEZ RODRÍGUEZ, Santiago y ALONSO CASTROVIEJO, Juan José (1996): “Especialización agraria en el Alto Ebro (La Rioja): La cultura del vino, 1500-1900", Brocar: Cuadernos de Investigación histórica, 20, pp. 211-235. 
LARREA BEOBIDE, Ángel (1995): El patronato de laicos en la Vizcaya del Antiguo Régimen, Bilbao, Universidad de Deusto.

LINDERT, Peter H.; MILANOVIC, Branco y WILLIAMSON, Jeffrey G. (2007): "Measuring Ancient Inequality", MPRA Paper No. 5388, posted 07, November 2007.

LLOPIS, Enrique; JEREZ, Miguel; ÁLVARO, Adoración y FERNÁNDEZ, Eva (2000): “Índices de precios de la zona noroccidental de Castilla-León, 1518-1650", Revista de Historia Económica, Año XVIII, n. a 3, pp. 665-686.

LLOPIS, Enrique y JEREZ, Miguel (2001): “El mercado de trigo en Castilla y León, 1691-1788: arbitraje espacial e intervención", Historia Agraria, n. ${ }^{\circ}$ 25, pp. 13-68.

LLOPIS, Enrique y SEBASTIÁN, José Antonio (2007): “La economía española del Antiguo Régimen. Balance y legado", en DOBADO, Rafael; GÓMEZ GALVARRIATO, Aurora y MÁRQUEZ, Graciela (comps.), México y España ¿Historias económicas semejantes?, México D. F., Fondo de Cultura Económica, pp. 77-135.

MARCOS MARTÍN, Alberto (2000): España en los siglos XVI, XVII y XVIII, Barcelona, Crítica/Caja Duero.

MARTIN ACEÑA, Pablo (1992): "Los precios en Europa durante los siglos XVI y XVII: estudio comparativo", Revista de Historia Económica, Año X, n. ${ }^{\circ}$ 3, 1992, pp. 359-395.

MORENO FERNÁNDEZ, José Ramón (1996): “La ganadería trashumante en La Rioja, 1752-1865. Una revisión bibliográfica y cuantitativa”, Brocar: Cuadernos de Investigación histórica, 20, pp. 277-302.

MORENO LÁZARO, Javier (2001): “Precios de las subsistencias, salarios nominales y niveles de vida en Castilla La Vieja. Palencia, 1751-1861", Documentos de Trabajo, Asociación española de Historia Económica, DT-AEHE n. ${ }^{\circ} 01001$.

MORGADO GARCÍA, Arturo (1996): El estamento eclesiástico y la vida espiritual en la diócesis de Cádiz en el siglo XVIII, Cádiz, Universidad de Cádiz.

-(2000): Ser clérigo en la España del Antiguo Régimen, Cádiz, Universidad de Cádiz.

MUÑOZ DUEÑAS, M. ${ }^{a}$ Dolores (1988): El diezmo en el Obispado de Córdoba (16501845), Córdoba, Caja de Ahorros.

REHER, David y BALLESTEROS, Esmeralda (1993): “Precios y salarios en Castilla la Nueva: La construcción de un índice de salarios reales, 1501-1991", Revista de Historia Económica, Año n. ${ }^{\circ} \mathrm{XI},{ }^{\circ}{ }^{\circ} 1$, pp. 101-151.

REY CASTELAO, Ofelia (1992): “El reparto social del diezmo en Galicia”, Obradorio de Historia Moderna, 1, 99, pp. 145-162.

RODRÍGUEZ LÓPEZ-BREA, Carlos (1995): “La crisis del Antiguo Régimen en el Arzobispado de Toledo. El impago de diezmos (1800-1820)", en DONEZAR, Javier M. a y PÉREZ LEDESMA, Manuel (eds.), Antiguo Régimen y Liberalismo. Homenaje a Miguel Artola. 2 Economía y sociedad, Madrid, Alianza Editorial, pp. 285-294.

SAAVEDRA, Pegerto (1992): A vida cotiá en Galicia de 1550-1850, Santiago de Compostela, Universidad de Santiago de Compostela.

SALOMON, Noël (1982): La vida rural castellana en tiempos de Felipe II, Barcelona, Ariel Historia. 


\section{APÉNDICE 1}

CABILDOS, POBLACIÓN Y TERRITORIO EN EL OBISPADO DE CALAHORRA

Y LA CALZADA. 1545-1771

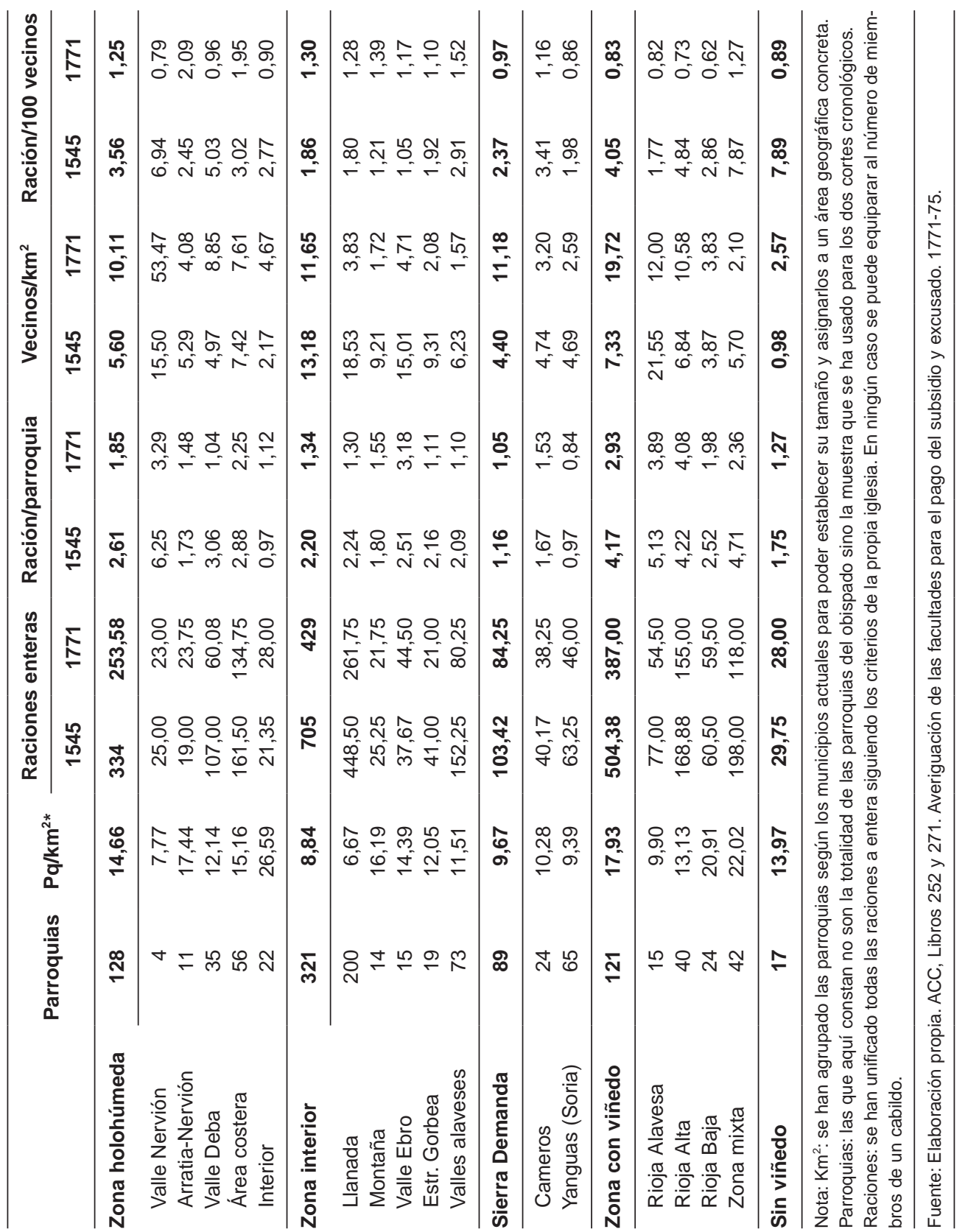




\section{APÉNDICE 2}

PRODUCTO AGRARIO POR HABITANTE, CASA EXCUSADA Y RACIÓN ENTERA. 1545-1771 (PROMEDIOS ANUALES EN HL)

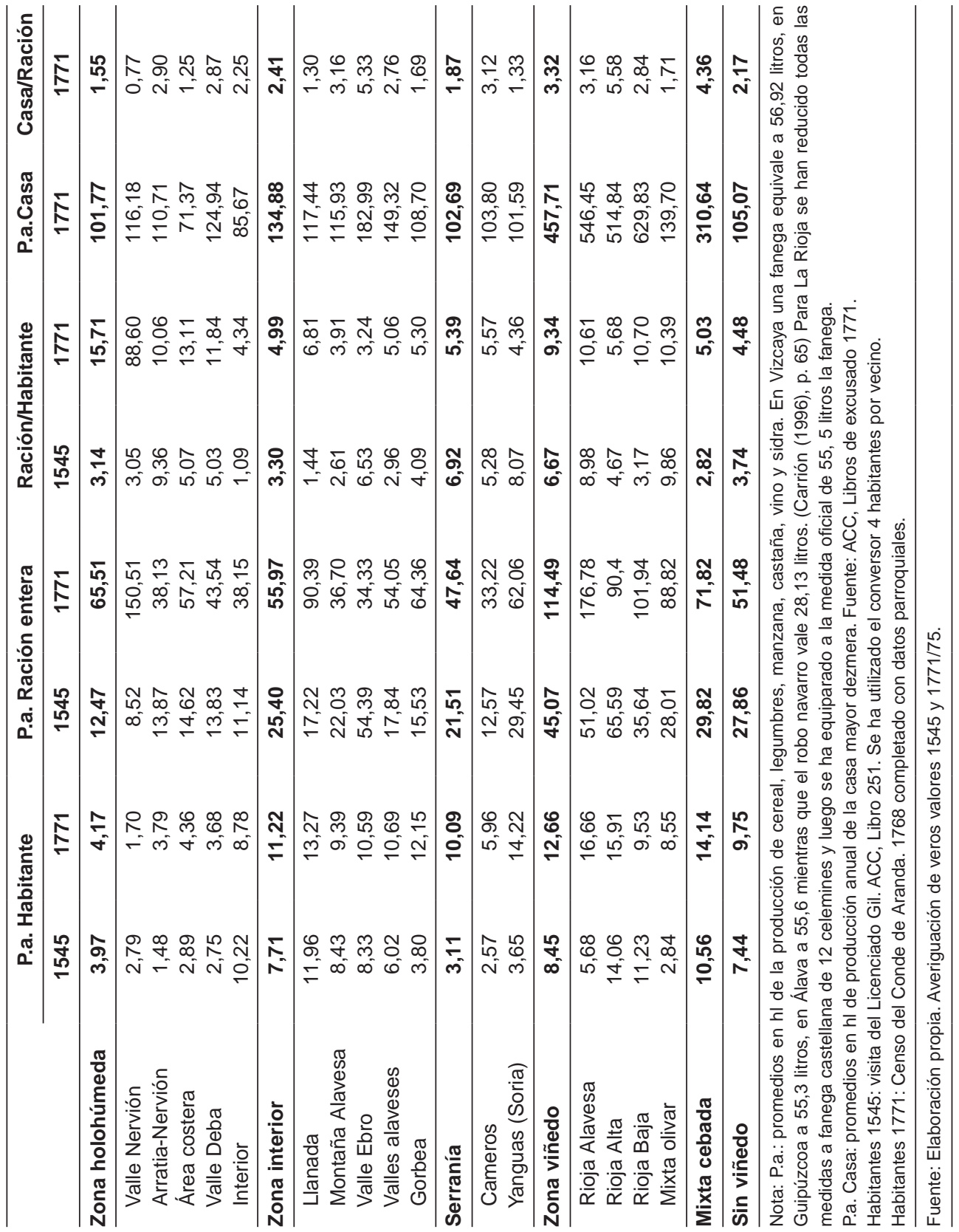




\section{APÉNDICE 3}

ESTRUCTURA DEL PRODUCTO AGRARIO DE UN BENEFICIADO ENTERO EN EL OBISPADO DE CALAHORRA Y LA CALZADA (\% SOBRE VALOR MONETARIO)

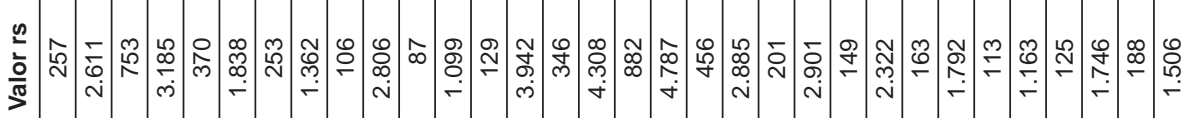

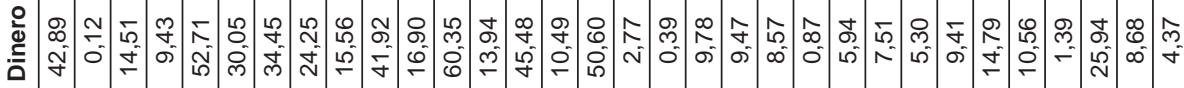

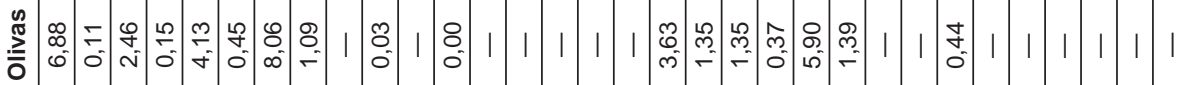

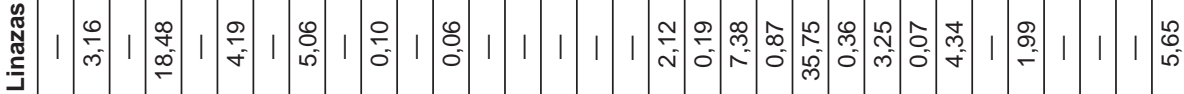

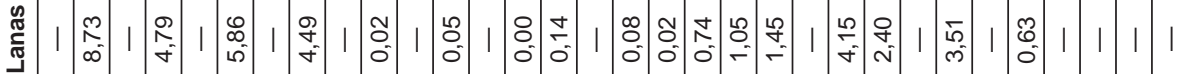

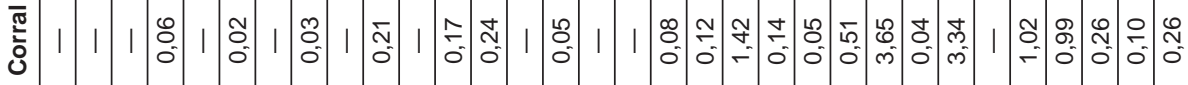

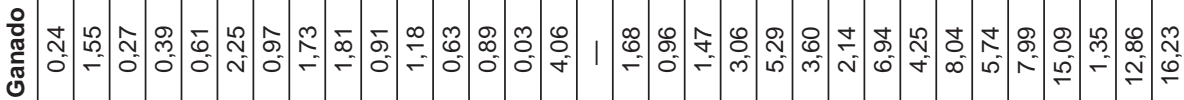

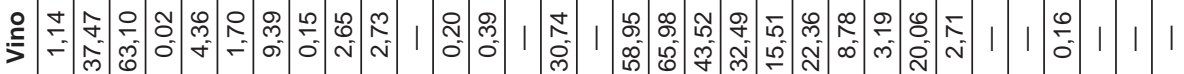

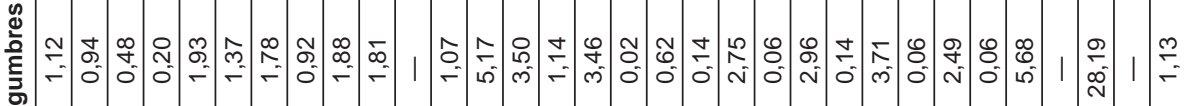
寻 을 育

ฮ 仓்

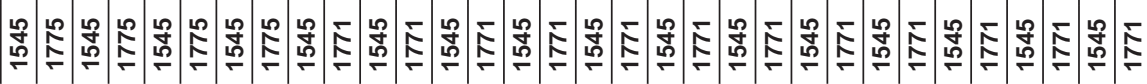

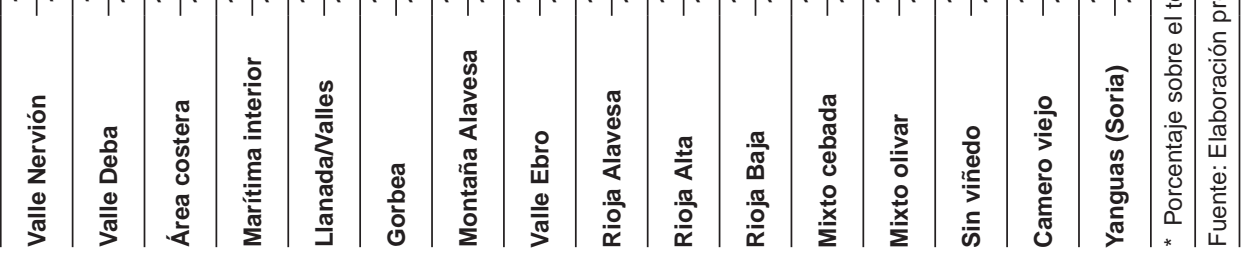




\section{APÉNDICE 4}

RÁNKING BENEFICIAL EN EL OBISPADO DE CALAHORRA Y LA CALZADA. 1545-1775

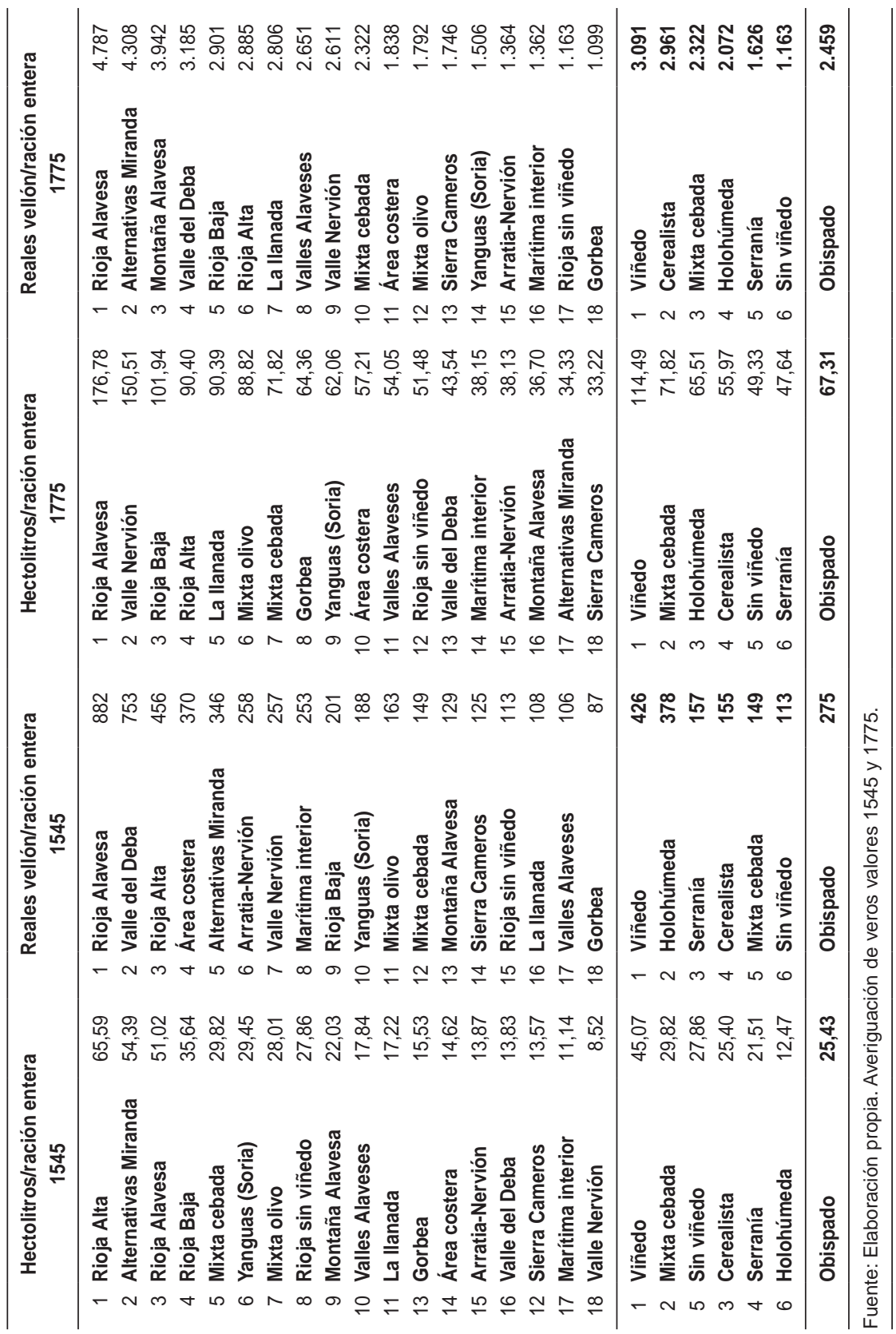

